\title{
The Practice Guideline for Vaccinating Korean Patients With Autoimmune Inflammatory Rheumatic Disease
}

\author{
Yu Bin Seo, M.D., Ph.D. ${ }^{1, *}$, Su-Jin Moon, M.D., Ph.D. ${ }^{2, *}$, Chan Hong Jeon, M.D., Ph.D. ${ }^{3}$, Joon Young Song, M.D., Ph.D. ${ }^{4}$, \\ Yoon-Kyoung Sung, M.D., Ph.D., MPH. ${ }^{5}$, Su Jin Jeong, M.D., Ph.D. ${ }^{6}$, Ki Tae Kwon, M.D., Ph.D. ${ }^{7}$, Eu Suk Kim, M.D., Ph.D. ${ }^{8}$, \\ Jae-Hoon Kim, M.D., Ph.D. ${ }^{9}$, Hyoun-Ah Kim, M.D., Ph.D. ${ }^{10}$, Dong-jin Park, M.D., Ph.D. ${ }^{11}$, Sung-Hoon Park, M.D., Ph.D. ${ }^{12}$ \\ Jin Kyun Park, M.D., Ph.D. ${ }^{13}$, Joong Kyong Ahn, M.D., Ph.D. ${ }^{14}$, Ji Seon Oh, M.D., Ph.D. ${ }^{15}$, Jae Won Yun, M.D., Ph.D. ${ }^{16}{ }^{\prime}$, \\ Joo-Hyun Lee, M.D., Ph.D. ${ }^{17}$, , Hee Young Lee, M.D., Ph.D. ${ }^{18},{ }^{\prime}$ Min Joo Choi, M.D., Ph.D. ${ }^{19}$, , Won Suk Choi, M.D., Ph.D. ${ }^{20}{ }^{\prime}$ \\ Young Hwa Choi, M.D., Ph.D. ${ }^{21}$, Jung-Hyun Choi, M.D., Ph.D. ${ }^{22}$, Jung Yeon Heo, M.D., Ph.D. ${ }^{21}$,
} Hee Jin Cheong, M.D., Ph.D. ${ }^{4}$, Shin-Seok Lee, M.D., Ph.D. ${ }^{11}$

${ }^{1}$ Division of Infectious Diseases, Department of Internal Medicine, College of Medicine, Hallym University, Chuncheon, ${ }^{2}$ Division of Rheumatology, Department of Internal Medicine, Uijeongbu St. Mary's Hospital, College of Medicine, The Catholic University of Korea, Uijeongbu, 'Division of Rheumatology, Department of Internal Medicine, Soonchunhyang University Bucheon Hospital, Bucheon, ${ }^{4}$ Division of Infectious Diseases, Department of Internal Medicine, Korea University Guro Hospital, Korea University College of Medicine, ${ }^{5}$ Department of Rheumatology, Hanyang University Hospital for Rheumatic Diseases, 'Division of Infectious Diseases, Department of Internal Medicine, Severance Hospital, Yonsei University College of Medicine, Seoul, 'Division of Infectious Diseases, Department of Internal Medicine, Kyungpook National University Chilgok Hospital, School of Medicine, Kyungpook National University, Daegu, ${ }^{8}$ Division of Infectious Diseases, Department of Internal Medicine, Seoul National University Bundang Hospital, Seongnam, ${ }^{9}$ Department of Rheumatology, Korea University Guro Hospital, Seoul, ${ }^{10}$ Department of Rheumatology, Ajou University Hospital, Ajou University School of Medicine, Suwon, ${ }^{11}$ Department of Rheumatology, Chonnam National University Medical School and Hospital, Gwangju, ${ }^{12}$ Division of Rheumatology, Department of Internal Medicine, Daegu Catholic University Medical Center, Daegu Catholic University School of Medicine, Daegu, ${ }^{13}$ Division of Rheumatology, Department of Internal Medicine, Seoul National University Hospital, Seoul National University College of Medicine, ${ }^{14}$ Division of Rheumatology, Department of Internal Medicine, Kangbuk Samsung Hospital, Sungkyunkwan University School of Medicine, ${ }^{15}$ Department of Information Medicine, Asan Medical Center, Seoul, ${ }^{16}$ Division of Infectious Disease Control, Korea Centers for Disease Control and Prevention, Osong, ${ }^{17}$ Division of Rheumatology, Department of Internal Medicine, Inje University Ilsan Paik Hospital, Inje University College of Medicine, Goyang, ${ }^{18}$ Center for Preventive Medicine and Public Health, Seoul National University Bundang Hospital, Seongnam, ${ }^{19}$ Division of Infectious Disease, Department of Internal Medicine, Catholic Kwandong University International St. Mary's Hospital, Incheon, ${ }^{20}$ Division of Infectious Diseases, Department of Internal Medicine, Korea University Ansan Hospital, Korea University College of Medicine, Ansan, ${ }^{21}$ Department of Infectious Diseases, Ajou University Hospital, Ajou University School of Medicine, Suwon, ${ }^{22}$ Division of Infectious Diseases, Department of Internal Medicine, The Catholic University of Korea, Eunpyeong St. Mary's Hospital, Seoul, Korea

To develop a clinical practice guideline for vaccination in patients with autoimmune inflammatory rheumatic disease (AIIRD), the Korean College of Rheumatology and the Korean Society of Infectious Diseases developed a clinical practice guideline according to the clinical practice guideline development manual. Since vaccination is unlikely to cause AIIRD or worsen disease activities, required vaccinations are recommended. Once patients are diagnosed with AIIRD, treatment strategies should be established and, at the same time, monitor their vaccination history. It is recommended to administer vaccines when the disease enters the stabilized stage. Administering live attenuated vaccines in patients with AIIRD who are taking immunosuppressants should be avoided. Vaccination should be considered in patients with AIIRD, prior to initiating immunosuppressants. It is recommended to administer influenza, Streptococcus pneumoniae, hepatitis A, hepatitis B, herpes zoster, measles-mumps-rubella virus, human papillomavirus, and tetanus-diphtheria-pertussis vaccines in patients with AIIRD; such patients who planned to travel are generally recommended to be vaccinated at the recommended vaccine level of healthy adults. Those who live in a household with patients with AIIRD and their caregivers should also be vaccinated at levels that are generally recommended for healthy adults. (J Rheum Dis 2020;27:182-202)

Key Words. Autoimmune inflammatory rheumatic disease, Vaccine, Immunization, Guideline

Received : May 28, 2020, Revised : June 9, 2020, Accepted : June 9, 2020

Corresponding to : Shin-Seok Lee (1Dhttp://orcid.org/0000-0001-6810-7355

Department of Rheumatology, Chonnam National University Medical School and Hospital 42 Jebong-ro, Dong-gu, Gwangju 61469, Korea. E-mail : shinseok@chonnam.ac.kr

Hee Jin Cheong (iD http://orcid.org/0000-0002-2532-1463

Division of Infectious Diseases, Department of Internal Medicine, Korea University Guro Hospital, Korea University College of Medicine, 148 Gurodong-ro, Guro-gu, Seoul 08308, Korea. E-mail : heejinmd@korea.ac.kr

*These authors contributed equally to this work.

This article is published simultaneously in the July 2020 issue of Infection and Chemotherapy.

Copyright (c) 2020 by The Korean College of Rheumatology.

This is an Open Access article, which permits unrestricted non-commerical use, distribution, and reproduction in any medium, provided the original work is properly cited. 


\section{INTRODUCTION}

Autoimmune inflammatory rheumatic disease (AIIRD) involves various organs due to immune dysregulation; although, causes have not been identified. In general, patients with AIIRD are at relatively high risk for infectious diseases compared to the general population [1-4]. This is due to loss of the normal immune response in the pathogenesis of the disease itself but is also associated with drug-related factors, such as glucocorticoid and other immunosuppressants, during treatment. In addition, comorbidities, such as Felty's syndrome and interstitial pneumonia, and disabilities caused by the diseases or operations are also identified as risk factors. As the causes of the diseases have recently started to be discovered, targeted therapies, such as biologic agents and small molecule inhibitors, have been developed and widely used which may increase the possibility of new opportunistic infections that are different from what are related to conventional immunosuppressants $[5,6]$.

In general, vaccination is one of the most effective methods for preventing infectious diseases. However, patients with AIIRD have not been adequately vaccinated to date despite their necessity $[7,8]$. The most significant reason is potentially the lack of understanding of the necessity of vaccination among healthcare providers who treat the disease and the patients. Although they understand the necessity, there seems to be concern regarding the possibility that vaccination can worsen the AIIRDs' activity or that vaccination may not be effective for patients with AIIRD to acquire adequate immunity. Numerous clinical practice guidelines have been published around the world to promote the interest of doctors and patients and raise their awareness regarding the latest knowledge. Many efforts have been made to inform the global medical community regarding the latest information on the vaccination of patients with AIIRD and induce suitable changes in practice patterns.

In line with changes in clinical settings and the trends in the development of practice guidelines at home and abroad, there has also been a growing need for a practice guideline for vaccinating patients with AIIRD in Korea considering its health care system, practice patterns, and environmental characteristics. To develop a practice guideline for vaccination, the Korean Society of Infectious Diseases (KSID) and the Korean College of Rheumatology (KCR) formed a vaccination guideline development committee composed of rheumatologists who diagnose and treat AIIRD, vaccine experts, and research methodologists. The total time for the guideline to be developed was 2 years and 6 months, between June 2017 and December 2019. This guideline is intended for experts in rheumatology and infectious diseases and for primary care providers who encounter patients with AIIRD intending to inform them of primary vaccines, methods to administer vaccines, and considerations in vaccination.

\section{DEVELOPMENT OF CLINICAL GUIDELINE}

\section{Determination of targeted patients and vaccines of practice guideline}

The targeted patients of this practice guideline include adults with AIIRD who are aged $\geq 19$ years excluding children while targeting the following AIIRD diseases: rheumatoid arthritis; systemic lupus erythematosus; antiphospholipid syndrome; adult still's disease; systemic sclerosis; scleroderma; relapsing polychondritis; polymyalgia rheumatica; mixed connective tissue disease; spondyloarthritis; Behçet's disease; vasculitis; granulomatosis with polyangiitis (Wegener's granulomatosis); eosinophilic granulomatosis with polyangiitis (Churg-Strauss syndrome); polyarteritis nodosa; Takayasu's arteritis; giant cell arteritis; Goodpasture syndrome; cryoglobulinemic vasculitis; dermatomyositis; polymyositis; amyopathic dermatomyositis; inclusion body myositis; antisynthetase syndrome; eosinophilic myositis; eosinophilic fasciitis; psoriatic arthritis; and periodic fever syndrome. The vaccines included in this practice guideline were limited to those primarily recommended for adults as follows: influenza vaccine; pneumococcal vaccine; hepatitis B vaccine; hepatitis A vaccine; human papillomavirus (HPV) vaccine; tetanus-diphtheria-pertussis vaccine; herpes zoster vaccine; and measles-mumps-rubella (MMR) vaccine.

\section{Formation of the practice guideline development committee and the working committee}

A practice guideline development committee was formed, composed of four rheumatologists, four infectious disease specialists, and one preventive medicine specialist to determine targeted patients and vaccines, discuss methods to develop a detailed practice guideline, and key questions. A separate working committee was also formed, composed of seven rheumatologists and seven infectious disease specialists, to review key questions related to each vaccine and develop recommendations. 
Those with a conflict of interest to any vaccine product were excluded from the committees.

As no sufficient evidence of the efficacy and safety of vaccination of patients with AIIRD was available, existing evidence-based practice guidelines were adapted. Additionally, to provide up-to-date information, we reviewed and incorporated the results of studies that were published after the search period of the most recent guideline. The additionally reviewed knowledge was limited to vaccines that have been recently and actively researched including the pneumococcal, HPV, and tetanus-diphtheria-pertussis vaccines. This practice guideline was developed as per the clinical practice guideline development manual distributed by the National Evidence-based healthcare Collaborating Agency [9].

\section{Selection of key questions for practice guideline}

Key questions were developed by the practice guideline development committee through discussion based on questions that can be raised in clinical settings, and the developed key questions were divided into general questions related to vaccination and specific questions on individual vaccines. At first, 14 general questions about vaccination and 19 questions about individual vaccines were developed. Since the answers to some questions were not supported by evidence, existing practice guidelines and studies were reviewed and 18 key questions were selected and revised. They were secondarily reviewed by the Working Committee, and the final 15 key questions were selected considering the existence of evidence for the questions and their applicability in Korea (Table 1).

\section{Searches and selection of existing practice guidelines}

Practice guidelines were searched using combinations of keywords including vaccine, autoimmune inflammatory rheumatic disease and medication. Search terms included the following vaccines: influenza vaccine; pneumococcal vaccine; hepatitis B vaccine; hepatitis A vaccine; HPV vaccine; tetanus-diphtheria-pertussis vaccine; herpes zoster vaccine; and MMR vaccine. The rheumatoid diseases included in this guideline are as follows: rheumatoid arthritis; systemic lupus erythematosus; antiphospholipid syndrome; adult still's disease; systemic sclerosis; scleroderma; relapsing polychondritis; polymyalgia rheumatica; mixed connective tissue disease; spondylarthritis; Behçet's disease; vasculitis; granulomatosis with polyangiitis (Wegener's granulomatosis); eosinophilic granulomatosis with polyangiitis (Churg-Strauss syndrome); polyarteritis nodosa; Takayasu's arteritis; giant cell arteritis; Goodpasture syndrome; cryoglobulinemic vasculitis; dermatomyositis; polymyositis; amyopathic dermatomyositis; inclusion body myositis; antisynthetase syndrome; eosinophilic myositis; eosinophilic fasciitis; psoriatic arthritis; and periodic fever syndrome. The drugs included in this guideline are: disease-modifying antirheumatic drugs (DMARD); tumor necrosis factor-alpha (TNF- $\alpha$ ) blocking agent; glucocorticoid; methotrexate; sulfasalazine; leflunomide; hydroxychloroquine; azathioprine; mycophenolate; cyclosporine; cyclopho-

Table 1. List of Key Questions

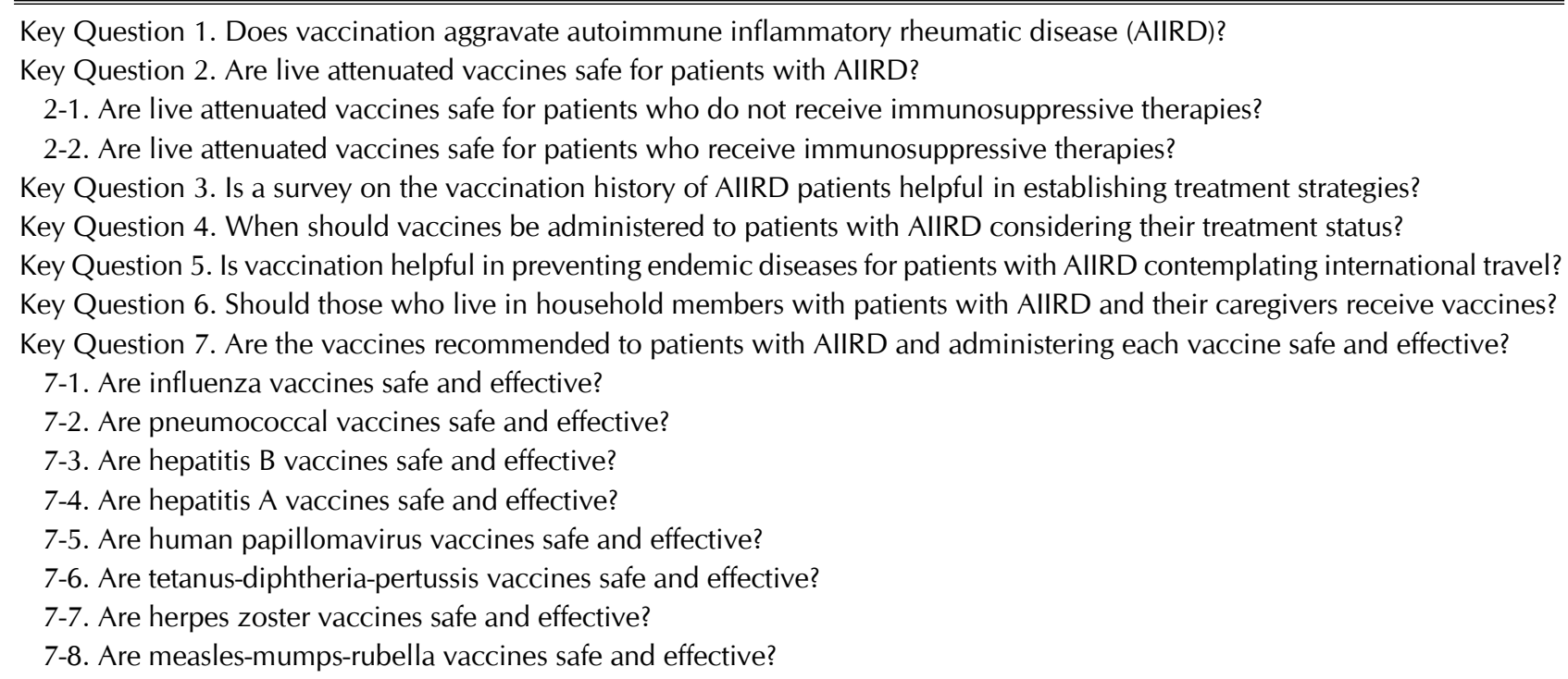


sphamide; tacrolimus; cyclophosphamide; infliximab; etanercept; abatacept; adalimumab; golimumab; rituximab; belimumab; tocilizumab; certolizumab; ustekinumab; canakinumab; and anakinra. The documents published between January 2010 and August 2018 were searched and a total of 13 practice guidelines written in English were obtained from websites including PubMed, OVID-EMBASE, and Guidelines International Network. We reviewed the content of 13 practice guidelines to preliminarily determine whether they fit the criteria to be included in the development of this practice guideline. Out of a total of 13 practice guidelines, five that were solely limited to medicines, and two that were mainly focused on healthy individuals, rather than vaccination of patients with AIIRD, were excluded. Then, a secondary screening was performed on the guidelines that were initially searched to identify the authors, whether they were evidence-based guidelines, and whether the recommendation grades were described. For each practice guideline, three guideline development and working committee members, using the Appraisal of Guidelines Research and Evaluation (AGREE) II, an appraisal tool for practice guidelines, scored the following items: their scope and objective; management of conflicts of interest; rigidity of development; clarity of expressions; applicability; and independence of editing. Based on the results, a total of six

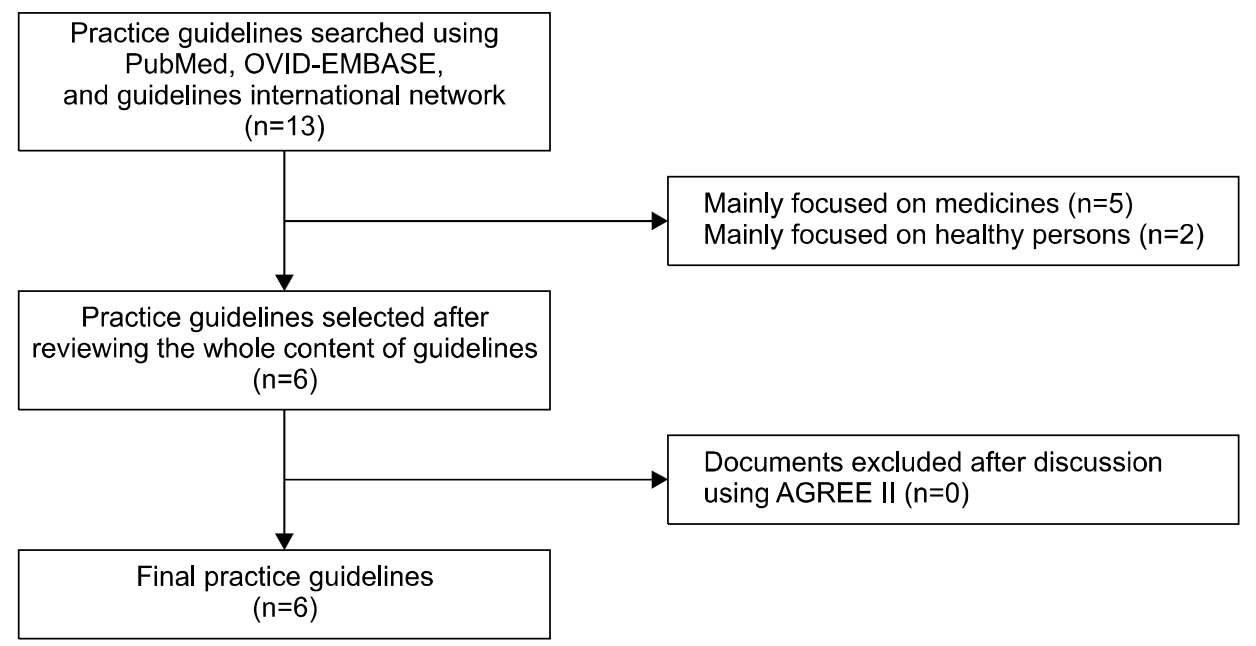

Figure 1. Procedure for searching and screening literature for adapting a practice guideline. AGREE: Appraisal of Guidelines Research and Evaluation.

Table 2. Final practice guidelines selected through an appraisal using AGREE II

\begin{tabular}{|c|c|c|c|c|}
\hline & Title & Country/area & Organization & Year of publication \\
\hline 1 & $\begin{array}{l}\text { EULAR recommendations for vaccination in adult patients } \\
\text { with autoimmune inflammatory rheumatic diseases }\end{array}$ & Europe & $\begin{array}{l}\text { European League Against } \\
\text { Rheumatism }\end{array}$ & 2011 \\
\hline 2 & $\begin{array}{l}\text { Canadian Rheumatology association recommendations for } \\
\text { the pharmacological management of rheumatoid arthritis } \\
\text { with traditional and biologic disease-modifying } \\
\text { antirheumatic drugs: part II safety }\end{array}$ & Canada & $\begin{array}{l}\text { Canadian Rheumatology } \\
\text { Association }\end{array}$ & 2012 \\
\hline 3 & $\begin{array}{l}\text { Clinical practice guideline for vaccination of the } \\
\text { immunocompromised host }\end{array}$ & USA & $\begin{array}{l}\text { Infectious } \\
\text { Diseases Society of } \\
\text { America }\end{array}$ & 2013 \\
\hline 4 & $\begin{array}{l}2015 \text { American College of Rheumatology guideline for the } \\
\text { treatment of rheumatoid arthritis }\end{array}$ & USA & $\begin{array}{l}\text { American College of } \\
\text { Rheumatology }\end{array}$ & 2015 \\
\hline 5 & $\begin{array}{l}\text { Vaccination recommendations for adult patients with } \\
\text { autoimmune inflammatory rheumatic diseases }\end{array}$ & Switzerland & $\begin{array}{l}\text { The Federal Commission } \\
\text { for Swiss Vaccination } \\
\text { Issues }\end{array}$ & 2015 \\
\hline 6 & $\begin{array}{l}\text { Recommendations for vaccination in adult patients with } \\
\text { systemic inflammatory rheumatic diseases from the } \\
\text { Portuguese Society of Rheumatology }\end{array}$ & Portugal & $\begin{array}{l}\text { Portuguese Society of } \\
\text { Rheumatology }\end{array}$ & 2016 \\
\hline
\end{tabular}

AGREE: Appraisal of Guidelines Research and Evaluation, EULAR: European League Against Rheumatism. 
practice guidelines suitable for adaptation were finally selected (Figure 1, Table 2).

\section{Review of the procedure for writing the practice guideline and up-to-datedness}

The practice guideline development committee, comprehensively reviewed and collected recommendations provided in the selected six practice guidelines focusing on the key questions selected by the committee, while the working committee described recommendations for key questions and their evidence, based on the collected content and the latest studies. The level of evidence (LOE) of each recommendation was graded following the GRADE (Grading of Recommendations Assessment, Development and Evaluation) methodology into high, moderate, low and very low, and the strength of recommendation (SOR) was classified into strong recommendation, weak recommendation, weak against, and strong against (Tables 3 and 4).

An additional literature review was conducted on the pneumococcal, HPV, and tetanus-diphtheria-pertussis vaccines, out of the eight vaccines addressed in this guideline because they have been actively researched on the targets of vaccines, immunogenicity, changes in vaccination methods and new vaccines. PubMed and EMBASE were used to search for data. Since the selected six practice guidelines were searched among publications released by October 2014, those published between November 2014 and October 2018 were additionally searched to review their up-to-datedness. We limited our search to systematic reviews, randomized controlled studies, cohort studies, case-control studies, and guidelines written in English. We applied the same keywords used to search the practice guidelines mentioned above. The title and abstract of the searched studies were reviewed by the practice guideline development committee

Table 3. Definition of level of evidence (LOE)

\begin{tabular}{ll}
\hline \hline \multicolumn{1}{c}{ LOE } & \multicolumn{1}{c}{ Description } \\
\hline High & $\begin{array}{c}\text { Very unlikely to change confidence in the } \\
\text { estimate of effect by an additional study } \\
\text { Moderate } \\
\text { Likely to change confidence in the estimate of } \\
\text { effect by an additional study } \\
\text { Lighly likely to change confidence in the } \\
\text { Very low }\end{array}$ \\
$\begin{array}{l}\text { estimate of effect by an additional study } \\
\text { effect }\end{array}$ \\
\hline
\end{tabular}

and their fitness for this study's purpose was cross-confirmed by two individuals. Those that failed to reach consensus were reviewed by two individuals together to determine whether to include them. Out of 445 studies first searched regarding the pneumococcal vaccine, six were included in the final review; out of 902 studies regarding the HPV vaccine, seven were included; out of 925 studies regarding the tetanus-diphtheria-pertussis vaccine, six were included. The selected studies were transferred to the working committee to be utilized in writing this practice guideline (Table 5).

\section{Survey on consensus of recommendations in the practice guideline}

Data on general recommendations for vaccination and recommendations for each vaccine were shared online among 23 members of the practice guideline development and working committees who reviewed them. To reach a consensus on each recommendation among them, face-to-face meetings were additionally held. Prior to building consensus, it was confirmed whether those involved in the development of this guideline had received support regarding the targeted vaccines and medications. They expressed agreement and disagreement based on the existing practice guidelines, the latest findings, the current status of the Korean medical services, the benefits of the vaccines, and abnormal responses. They scored their agreement with each recommendation using a 9-point scale; when the score of over $80 \%$ of committee members reached between $7 \sim 9$ points, it was considered that the recommendation reached a consensus. When they failed to reach a consensus on a certain recom-

Table 4. Definition of strength of recommendation (SOR)

\begin{tabular}{lc}
\hline \hline \multicolumn{1}{c}{ SOR } & \multicolumn{1}{c}{ Description } \\
\hline $\begin{array}{l}\text { Strong } \\
\text { recommendation }\end{array}$ & $\begin{array}{c}\text { Recommended to follow the course of } \\
\text { action because there is sufficient } \\
\text { evidence of desirable effects } \\
\text { recommendation } \\
\text { Recommended to conditionally provide } \\
\text { the course of action (test) or to provide } \\
\text { it for certain individuals at the } \\
\text { discretion of specialty providers } \\
\text { Weak against }\end{array}$ \\
$\begin{array}{c}\text { Recommended not to follow the course } \\
\text { of action, if feasible, because there is } \\
\text { some evidence of undesirable effects } \\
\text { Recommended not to follow the course } \\
\text { of action because there is sufficient } \\
\text { evidence of undesirable effects }\end{array}$ \\
\hline
\end{tabular}


Table 5. The literature reviewed to reflect the latest knowledge

\begin{tabular}{|c|c|c|c|}
\hline & Title & Study design & Year of publication \\
\hline 1 & Immunizations following solid-organ transplantation & Review & 2014 \\
\hline 2 & $\begin{array}{l}\text { Immunogenicity and safety of the bivalent human papilloma virus (HPV) } \\
\text { vaccine in female patients with juvenile idiopathic arthritis: a prospective } \\
\text { controlled observational cohort study }\end{array}$ & Case-control study & 2014 \\
\hline 3 & $\begin{array}{l}\text { Effect of abatacepton the immunogenicity of 23-valent pneumococcal } \\
\text { polysaccharide vaccination (PPSV23) in rheumatoid arthritis patients }\end{array}$ & $\begin{array}{l}\text { Randomized } \\
\text { controlled study }\end{array}$ & 2015 \\
\hline 4 & $\begin{array}{l}\text { Opsonic and antibody responses to pneumococcal polysaccharide in } \\
\text { rheumatoid arthritis patients receiving golimumab plus methotrexate }\end{array}$ & $\begin{array}{l}\text { Randomized } \\
\text { controlled study }\end{array}$ & 2015 \\
\hline 5 & $\begin{array}{l}\text { The risk of pneumococcal infections after immunization with } \\
\text { pneumococcal conjugate vaccine compared to non-vaccinated } \\
\text { inflammatory arthritis patients }\end{array}$ & Case-control study & 2015 \\
\hline 6 & $\begin{array}{l}\text { The association between antibody levels before and after 7-valent } \\
\text { pneumococcal conjugate vaccine immunization and subsequent } \\
\text { pneumococcal infection in chronic arthritis patients }\end{array}$ & Case-control study & 2015 \\
\hline 7 & HPV vaccine trials and tribulations: clinical perspectives & Review & 2015 \\
\hline 8 & $\begin{array}{l}\text { Pertussis prevalence in Korean adolescents and adults with persistent } \\
\text { cough }\end{array}$ & $\begin{array}{l}\text { Retrospective } \\
\text { observation study }\end{array}$ & 2015 \\
\hline 9 & $\begin{array}{l}\text { Evaluation of the immunogenicity of the } 13 \text {-valent conjugated } \\
\text { pneumococcal vaccine in rheumatoid arthritis patients treated with } \\
\text { etanercept }\end{array}$ & Case-control study & 2016 \\
\hline 10 & $\begin{array}{l}\text { HPV infection and vaccination in Systemic Lupus Erythematosus patients: } \\
\text { what we really should know }\end{array}$ & Review & 2016 \\
\hline 11 & Recommended vaccinations for asplenic and hyposplenic adult patients & Review & 2016 \\
\hline 12 & Prophylactic HPV vaccination: past, present, and future & Review & 2016 \\
\hline 13 & Pneumococcal vaccination in autoimmune rheumatic diseases & Review & 2017 \\
\hline 14 & Committee opinion no. 704: human papillomavirus vaccination & Guideline & 2017 \\
\hline 15 & $\begin{array}{l}\text { Practice alert: Advisory Committee on Immunization Practices (ACIP) } \\
\text { vaccine update, } 2017\end{array}$ & Guideline & 2017 \\
\hline 16 & $\begin{array}{l}\text { Committee opinion no. 718: update on immunization and pregnancy: } \\
\text { tetanus, diphtheria, and pertussis vaccination }\end{array}$ & Guideline & 2017 \\
\hline 17 & $\begin{array}{l}\text { Tdap vaccination coverage during pregnancy - selected sites, United } \\
\text { States, 2006 } 2015\end{array}$ & $\begin{array}{l}\text { Retrospective } \\
\text { observation study }\end{array}$ & 2017 \\
\hline 18 & $\begin{array}{l}\text { Prevention of pertussis, tetanus, and diphtheria with vaccines in the } \\
\text { United States: recommendations of the ACIP }\end{array}$ & Guideline & 2018 \\
\hline 19 & Infections in pregnancy and the role of vaccines & Review & 2018 \\
\hline
\end{tabular}

Tdap: tetanus-diphtheria-pertussis, ACIP: Advisory Committee on Immunization Practices.

mendation, they revised and adjusted its strength through discussion, ultimately voting on a new recommendation to reach a consensus.

\section{Final review, approval, and distribution of the practice guideline}

The developed practice guideline was reviewed and approved by the external examiners selected by the KCR and the KSID. To receive feedback from patients with AIIRD who were vaccination targets, the guideline was shared with the Association of Rheumatoid Arthritis (RA), Systemic Lupus Erythematosus (SLE), Ankylosing
Spondylitis (AS) patients. The KCR and KSID agreed to jointly publish and distribute the final practice guideline. This guideline will be updated after 5 years according to newly published guidelines and studies.

\section{GENERAL RECOMMENDATIONS}

\section{KQ 1. Does vaccination aggravate AIIRD?}

Vaccination is unlikely to cause or aggravate AIIRD and generally recommended in AIIRD patients (LOE: Low/SOR: Strong recommendation). 
The possibility that vaccination causes AIIRD is low; however, autoimmune responses such as Guillain-Barré syndrome and idiopathic thrombocytopenic purpura (ITP) were reported after vaccination. It has been rarely reported that adjuvants can be a potential cause of AIIRD [10-17]. The majority of studies, however, have reported that vaccines can be safely administered without worsening underlying diseases, and large-scale epidemiological studies also reported that the degree of abnormal responses observed in patients with AIIRD was not different from that observed in the general population [18-20].

KQ 2. Are live attenuated vaccines safe for patients with AIIRD?

KQ 2-1. Are live attenuated vaccines safe for patients who do not receive immunosuppressive therapies?

If AIIRD patients need to take live attenuated vaccines, they have to take vaccination while they are not taking immunosuppressive agents (LOE: Very low/SOR: Strong recommendation).

KQ 2-2. Are live attenuated vaccines safe for patients who receive immunosuppressive therapies?

AIIRD Patients on immunosuppressive agents should not take live attenuated vaccines (LOE: Very low/SOR: Weak against).

The live attenuated vaccine is created by reducing the virulence of germs and viruses to lower the potential risk of infection while keeping immunogenicity. Unless there is a specific prohibition, live attenuated vaccines can be administered to patients with AIIRD who do not take immunosuppressive medications. However, since concern exists regarding potential severe infections by administering live attenuated vaccines to patients with AIIRD who take immunosuppressants, delivering these vaccines to the aforementioned patients should be avoided, when feasible. Recently, several biologic agents targeting patients with AIIRD have been developed and widely used; however, they must be cautiously administered as they lower immunity. The majority of studies also prohibit the administration of live attenuated vaccines to patients with AIIRD who are taking immunosuppressants [21-26]. Still, MMR, varicella, and herpes zoster vaccines can be restrictively considered depending on the level of immunosuppression by performing a risk-benefit analysis for individual patients. The risk of infections that may be caused by administering live attenuated vaccines can change depending on the type of vaccines and the level of immunosuppression. Herpes zoster vaccines can be considered for those who used a steroid for a short period within 2 weeks, and were given with a dose of $>20 \mathrm{mg}$ of prednisolone per day, a dose of $\geq 0.4 \mathrm{mg} / \mathrm{kg}$ of methotrexate per week, and a dose of $>3.0 \mathrm{mg} / \mathrm{kg}$ of azathioprine per day [23].

KQ 3. Is a survey on the vaccination history of AIIRD patients helpful in establishing treatment strategies? Once patients are diagnosed with AIIRD, their vaccination history needs to be surveyed while treatment strategies are being established (LOE: Expert opinion/SOR: Strong recommendation).

Vaccines should be safely administered to patients with AIIRD while keeping immunogenicity. Immunosuppressants are not often administered immediately after patients are diagnosed with AIIRD. In these cases, live attenuated vaccines can be safely administered to the patients prior to treatment initiation minimizing the reduction of immunogenicity caused by immunosuppressants. For this reason, it is important to check the vaccination history of patients with AIIRD prior to treatment of immunosuppressants. If any method to test antibodies related to target vaccines is available, the test needs to be conducted in the early stage of diagnosis and vaccination plans need to be established based on the test results.

KQ 4. When should vaccines be administered to patients with AIIRD considering their treatment status?

KQ 4-1. Vaccines need to be administered to patients when their AIIRD is in a stable state (LOE: Very low/SOR: Strong recommendation).

KQ 4-2. AIIRD patients have to get vaccinated, if feasible, before commencing immunosuppressive therapies (LOE: Very low/SOR: Strong recommendation).

Those who treat patients with AIIRD should recommend vaccination, if feasible, prior to the planned immunosuppression for proper immunity building and safe vaccination $[21-23,25,26]$. Since immunogenicity is generally created within 3 weeks after administering live attenuated vaccines, it is recommended to administer vaccines 4 weeks prior to planned immunosuppression (Table 6) [21]. The recommended timing, however, can 
Table 6. Recommended timing of vaccination after discontinuing AIIRD treatment by the type of AIIRD medications

\begin{tabular}{|c|c|c|c|c|}
\hline Drug category & Medication & Half-life period & Inactivated vaccine & Live attenuated vaccine \\
\hline Glucocorticoid & Prednisone & $3 \sim 4$ hours & No limitation to vaccination* & 1 month \\
\hline \multirow[t]{2}{*}{ Synthetic DMARD } & Methotrexate & $3 \sim 10$ hours & & $1 \sim 3$ months \\
\hline & Leflunomide & 14 days & & $3 \sim 24$ months \\
\hline \multirow[t]{8}{*}{ Biologic DMARD } & Etanercept & 4.3 days & & 1 month \\
\hline & Adalimumab & 14 days & & 3 month \\
\hline & Certolizumab & 14 days & & \\
\hline & Golimumab & 12 days & & \\
\hline & Infliximab & $8 \sim 10$ days & & \\
\hline & Abatacept & 13 days & & 3 month \\
\hline & Tocilizumab & 13 days & & \\
\hline & Rituximab & 21 days & \multicolumn{2}{|c|}{$6 \sim 12$ months } \\
\hline
\end{tabular}

AIIRD: Autoimmune Inflammatory Rheumatic Disease, DMARD: disease-modifying antirheumatic drugs. *Although there is no limitation to vaccination, decisions should be made in consideration of the urgency of vaccination and the level of immunosuppression.

differ depending on the type of immunosuppressants. When administering live vaccines prior to anti-TNF and rituximab therapies, it is recommended to separate them by a 4 -week interval, but in the case of administering abatacept or tocilizumab, an interval of $2 \sim 3$ weeks is recommended [27-31]. Unlike them, inactivated vaccines can be relatively safely administered while administering conventional DMARDs or biologic agents [22,26]. However, since immune responses can be slightly different depending on the type of administered immunosuppressive medications, vaccinations should be carefully performed. Combination therapies with methotrexate or anti-TNF drugs were reported to reduce the immunogenicity of vaccines, while no issue associated with the immunogenicity of influenza and pneumococcal vaccines was reported in a group to which adalimumab was solely administered [32-34]. While it was reported that humoral immune responses were reduced when abatacept was administered, no significant effect was observed in the group of tocilizumab $[35,36]$. Rituximab, a monoclonal antibody against the protein CD20, significantly reduces humoral immune responses due to loss of $\mathrm{B}$ cells, and for this reason, it is recommended to vaccinate patients at least 4 weeks prior to treatment [22,37]. As such, since immunosuppression can impede immune responses after vaccination, vaccination is recommended in general prior to treatment, but it is not recommended to delay treatment for AIIRD for completing vaccinations [21].

Since a decrease in the immunogenicity of vaccines caused by immunosuppressive therapies is dependent on the total amount of medications that a patient is taking, it would be better to administer vaccines to those who have already been receiving immunosuppressive therapies when the total amount of medications is the lowest [25]. In addition, the timing of administering live attenuated vaccines after discontinuation of immunosuppressive therapies differs depending on the type of medications and thus should be determined in consideration of the pharmacodynamic characteristics of medications [26]. In general, when taking $\geq 10 \sim 20 \mathrm{mg}$ of prednisolone for over 2 weeks, it is recognized as a high-dose steroid, and it is recommended to separate discontinuation of the medication and vaccination by a 4 -week interval $[38,39]$. When a large amount of medications were intravenously injected, it is recommended to suspend vaccination at least for 3 months [38]. When $0.4 \mathrm{mg} / \mathrm{kg} /$ week or 20 $\mathrm{mg}$ /week of methotrexate or more was administered, it is recommended to administer vaccines $1 \sim 3$ months after discontinuation of the medication $[25,40]$. In the case of leflunomide, due to its long half-life period, it is recommended to separate discontinuation of the medication and vaccination by the interval of $3 \sim 6$ months. However, it can remain in the body in an activated state for as long as 2 years; therefore, it is recommended to administer vaccines 2 years after discontinuation $[25,38,40]$. As etanercept, among anti-TNF drugs, has a relatively short half-life period compared to other medications, vaccination can be considered 1 month after administering the medication. Conversely, other medications including adalimumab, certolizumab, and infliximab should be discontinued for 3 months before administering vaccines 
$[25,38,40]$. In the case of biologic agents like abatacept, tocilizumab, and ustekinumab, it is recommended to administer vaccines 3 months ( 5 times their half-life period) after discontinuation. Regarding rituximab, however, it is recommended to separate discontinuation of the medication and vaccination by the interval of $6 \sim 12$ months both for live attenuated vaccines and inactivated vaccines considering the recovery period of $\mathrm{B}$ cells $[22,25,26,28-30,40]$.

KQ 5. Is vaccination helpful in preventing endemic diseases for patients with AIIRD contemplating international travel?

Patients with AIIRD contemplating travel have to receive vaccines as is generally recommended for healthy persons (LOE: Low/SOR: Strong recommendation).

Immunocompromised patients are more likely than healthy individuals to contract infectious diseases when on vacation to places where infectious diseases are endemic. For this reason, it is important to consult their doctor regarding vaccination in advance. Since some vaccines require multiple doses over a certain period, it is recommended to have a consultation 6 months before traveling; but, in case of an unexpected vacation, it is necessary to have a consultation as early as possible to increase patients' safety and immunogenicity [22]. The vaccines that are recommended for those contemplating travel to the aforementioned places include hepatitis $\mathrm{A}$ and $\mathrm{B}$, influenza, meningococcus, pneumococcus, tetanus, typhoid, cholera, rabies, tick-borne encephalitis virus, yellow fever, and MMR vaccines.

\section{1) Yellow fever vaccination}

Yellow fever is an endemic infectious disease in the tropical areas of Africa and the Central and South America, having a mortality rate of over $20 \%$ due to the absence of an effective cure. Therefore, those who contemplate travel to areas where yellow fever is endemic are required to receive yellow fever vaccines; however, since these vaccines, compared to other live attenuated vaccines, show a high virus replication capacity, patients who receive immunosuppressive therapies are not recommended to receive them due to their potential risk of infection [25]. In general, it is recommended for patients with AIIRD to avoid travel to areas where yellow fever is endemic; but, those who inevitably have to visit such areas should write a waiver that states the reason why they cannot be vaccinated [41].

KQ 6. Should those who live in a household with patients with AIIRD and their caregivers receive vaccines? Those who live in households with patients with AIIRD and their caregivers have to receive generally recommended vaccines. In particular, influenza, measles-mumps-rubella (MMR), varicella, and herpes zoster vaccines need to be administered based on the same schedules for healthy persons (LOE: Moderate/SOR: Strong recommendation).

Those who live in households with patients with AIIRD and are immunocompetent should be vaccinated according to the Korean guideline for vaccination. They should be vaccinated against influenza every year, and MMR, rotavirus, varicella, and herpes zoster vaccines should be administered according to their general recommendations [42-48]. In some cases, yellow fever and oral typhoid vaccines should be administered if necessary. However, as live vaccines can spread viruses after administration, those who received such vaccines, in general, need to be careful when in contact with patients who are receiving immunosuppressive therapies, for 2 weeks following vaccination. If there is any family member who was vaccinated against rotavirus, patients with AIIRD should avoid contacting the vaccinated family member's feces for 4 weeks and should maintain hand hygiene.

\section{VACCINATION RECOMMENDATIONS BY VACCINE}

\section{Influenza vaccine}

Patients with AIIRD have to take influenza vaccines every year (LOE: Moderate/SOR: Strong recommendation).

\section{1) Vaccination targets}

All patients with AIIRD should be vaccinated against influenza. There are only a few epidemiological studies on influenza infection targeting patients with AIIRD. A study that targeted individuals aged $\geq 65$ years reported that the number of those who were hospitalized due to influenza infections and complications increased in the group of patients with chronic diseases including rheu- 
matoid diseases and vasculitis [49]. A retrospective study, targeting 46,030 patients with rheumatoid arthritis reported that their influenza infection rate was high (409.33 vs. 306.12 persons/100,000 patients-days) and that the rate of complications was 2.75 times higher [50]. No relationship was observed between the increasing rates and the medications used for the patients. In general, since patients with AIIRD are judged to be more likely to contract influenza and complications, it is recommended to administer influenza vaccines to all patients with AIIRD, and most guidelines also recommend influenza vaccines as the highest priority vaccine.

\section{2) Effects and efficacy of vaccine}

The immunogenicity of patients with rheumatoid arthritis is similar to that of healthy individuals, and immunogenicity can be maintained even when conventional synthetic DMARDs (csDMARDs) or anti-TNF drugs [34,51-61] are administered. It has often been reported that the immunogenicity of patients with lupus is slightly decreased, and many studies reported no significant differences in immunogenicity between patients with lupus and healthy individuals $[18,20,57,62-70]$. Patients with granulomatosis with polyangiitis, systemic sclerosis, and Sjögren's syndrome were also reported to show no differences in immunogenicity compared to healthy persons [19,71-73]. Only few studies exist, regarding the effects of influenza vaccines on patients with AIIRD; however, a large-scale observational study that targeted patients with rheumatoid arthritis reported that the infection rate of the vaccinated group decreased by $17 \%$ (95\% confidence interval [CI], 5\% 29\%) [74]. Another study that targeted patients with rheumatoid arthritis and systemic erythematosus lupus also reported that the share of those who contracted pneumonia, acute bronchitis, and virus infection in the vaccinated group was significantly lower than that of the non-vaccinated group $[74,75]$. The immunogenicity of influenza vaccines can differ, depending on the use of immunosuppressants and the type of medications. However, it was reported that the immunogenicity of patients with AIIRD was generally similar to or slightly lower than that of healthy individuals.

\section{3) Safety of vaccine}

Inactivated influenza vaccines can be safely administered, even in an immunocompromised state. Their side effects in patients with AIIRD are not different from those in healthy persons $[51,57]$.

\section{4) Vaccination methods}

Since protective immunity to influenza can be sufficiently achieved when influenza vaccines are administered before influenza is prevalent, influenza vaccines should be administered prior to the prevalence of influenza, and even amid the prevalence of influenza, patients should be vaccinated as early as possible. In Korea, influenza is prevalent from November to April. A dose of intramuscular injection is administered in general, but the methods of administration can differ depending on the dosage of vaccines. Therefore, they should be administered following their respective instructions. When patients are receiving immunosuppressants, the timing of vaccination should be determined, considering the patients' disease, immunosuppression level, and half-life period of the medications.

\section{Pneumococcal vaccine}

Patients with AIIRD have to take pneumococcal vaccines (LOE: Low/SOR: Strong recommendation).

\section{1) Vaccination targets}

Streptococcus pneumoniae accounts for about 30\% 40\% of community-acquired pneumonia. The infection of $S$. pneumoniae can cause severe complications or death particularly in persons aged $\geq 65$ years, patients with chronic diseases, and immunocompromised patients. Although epidemiological data available on the infection of S. pneumoniae in patients with AIIRD are sufficient, it was reported that patients who used anti-TNF drugs showed a 5 times higher incidence of pneumonia (5.97/1,000 vs. $1.07 \sim 1.2 / 1,000$ patients-days) than healthy persons [76]. The mortality rate of patients with rheumatoid arthritis from pneumonia increased by $2 \sim 5$ times and the hospitalization rate of patients with rheumatoid arthritis is 2 times higher than that of general persons [77]. Since the share of those who contract infections and complications caused by $S$. pneumoniae among patients with AIIRD increases, all patients with AIIRD are recommended to be vaccinated against $S$. pneumoniae.

\section{2) Effects and efficacy of vaccine}

In general, the effects of $S$. pneumoniae vaccines on patients with AIIRD are nearly identical to those on healthy persons [78-84]. As for the effects of medications administered to patients with AIIRD on the immuno- 
genicity of vaccines, csDMARDs did not show any effect, while methotrexate, rituximab, and abatacept were reported to decrease immunogenicity. The immunogenicity of pneumoccal vaccines differed depending on the type of anti-TNF drugs in early studies. In a randomized controlled trial that studied the effect of a pneumococcal polysaccharide vaccine 23 (PPSV23) in patients with rheumatoid arthritis, the effect of pneumonia prevention was unclear. However, it was conducted on a small number of patients with a severe immunocompromised condition. Furthermore, some reports show reduced immunogenicity in some patient groups. Therefore, efforts to optimize the effects such as adjusting the timing of inoculation are necessary [85].

\section{3) Safety of vaccine}

Pneumococcal vaccines, as inactivated vaccines, can be administered regardless of the state of immunity, and do not affect the activity of AIIRD. No valid epidemiological study has been conducted yet regarding the safety of pneumococcal vaccines for patients with AIIRD [77]. It was reported that the aluminum salts used as a vaccine adjuvant may cause fever, pain at the injection site, and malaise and can cause autoimmune/inflammatory syndrome induced by adjuvants (ASIA); however, no study has been reported on streptococcal vaccines [86]. Yet, it was reported that both strong local and excessive systemic inflammatory responses were observed in patients with Behçet's disease after vaccination, thus making it necessary to carefully observe patients after vaccination [87]. Another study reported that abnormal responses to pneumococcal vaccines were observed in infants who were less than 1 year old and had Kawasaki disease [88].

\section{4) Vaccination methods}

As of 2019, 2 pneumococcal vaccines are available for adults: pneumococcal conjugate vaccine 13 (PCV13) and PPSV23. PCV13 shows good immunogenicity and also proved to be effective in preventing pneumonia in healthy adults. The finding that it is cost-effective to give both vaccines to high-risk patients of pneumococcal infection is true; therefore it is safe to administer both the PCV13 and the PPSV23 to adult patients with AIIRD [89]. A booster effect is caused when administering the PCV13 first, while a hypo-responsiveness is caused when administering the PPSV23 first; therefore, it is advisable to administer the PCV13 first [90].

(1) Unvaccinated patients against pneumococcal vac- cines: A dose of PCV13 should be administered first, and 1 dose of PPSV23 should be administered at least 8 weeks later. A dose of PPSV23 should be additionally administered 5 years after the last vaccination.

(2) Patients who were administered with 1 dose of PPSV23: A dose of PCV13 should be administered 1 year after the administration of PPSV23. A dose of PPSV23 should be additionally administered at least 8 weeks after the administration of PCV13 and 5 years after the previous administration of PPSV23.

(3) Patients who were administered with 2 doses of PPSV23: A dose of PCV13 should be administered 1 year after the last vaccination.

(4) Patients who were administered with a dose of PCV13 and 2 doses of PPSV23 before the age of 65: A dose of PPSV23 should be additionally administered after turning 65 , and 5 years after the previous administration of PPSV23.

\section{Hepatitis B vaccine}

AIIRD patients who have no hepatitis B antibody have to take Hepatitis B vaccines (LOE: Low/SOR: Strong recommendation).

\section{1) Vaccination targets}

The use of immunosuppressants in patients with AIIRD is likely to reactivate hepatitis $\mathrm{B}$, causing a high risk of complications [91-93]. A retrospective study that targeted 123 HBsAg-positive patients with rheumatoid arthritis reported that hepatitis B was reactivated in 30 patients (24.4\%) during treatment [94]. Multiple guidelines related to the vaccination of patients with AIIRD also recommend to vaccinate patients with AIIRD with no hepatitis B antibody (all HBsAg, anti-HBc, and anti-HBs-negative) and unvaccinated individuals. Hepatitis $B$ vaccines are more actively recommended for high-risk groups. The guidelines published by the KSID and the Korean Association for the Study of the Liver, the American College of Rheumatology, and the Canadian Rheumatology Association define hepatitis B high-risk groups as: those who abuse injection drugs; those who have sexual relations with multiple partners; those who travel or stay for a long time in areas where hepatitis B is prevalent; those who are frequently administered with blood components; male homosexuals; those who contact patients with hepatitis B; health care providers and 
laboratory workers who can be exposed to the hepatitis B virus [95,96]; patients with AIIRD who are being administered with biologic agents such as TNF-blockers and rituximab; and immunocompromised patients who are receiving high-dose steroid therapies [21].

\section{2) Effects and efficacy of vaccine}

It is generally recognized that the preventive effect of hepatitis $B$ vaccines can be achieved when the serum antibody reaches $10 \mathrm{IU} / \mathrm{L}$ after vaccination. When patients with AIIRD who had no hepatitis B antibody (all HBsAg, anti-HBc and anti-HBs-negative) were administered with 3 doses of hepatitis $B$ vaccines ( 0,1 , and 6 months), a relatively large percentage $(68 \% \sim 93 \%)$ showed an effective seroconversion rate. However, since those who are being administered with csDMARDs, biologic agents, and rituximab show a low seroconversion rate $(70 \%, 50 \%$, and $25 \%$ respectively), the generation of antibodies in those who receive immunosuppressants should be monitored after vaccination [97]. To monitor the generation of antibodies, the potency of anti-HBs antibodies should be measured $4 \sim 6$ weeks after the last vaccination. In the case that antibodies are not generated against hepatitis B after vaccination, it is recommended to administer 3 doses of hepatitis $B$ vaccines ( 0,1 , and 6 months).

Vaccination is expected to benefit patients with AIIRD at some extent, who are positive only for anti-HBc (negative for HBsAg and anti-HBs) thus suspecting a past hepatitis B virus exposure; however, no consistent practice guidelines are available that support it [98]. For those who are positive only for anti-HBc, the HBV DNA test should be performed to identify whether the state is false positive or latent infectious, and, if negative, vaccination can be considered [99].

\section{3) Safety of vaccine}

Inactivated hepatitis B vaccines can be safely administered when immunity is compromised. The side effects of hepatitis B vaccination in patients with AIIRD are not different from those in healthy persons. A study that compared 44 patients with rheumatoid arthritis with healthy controls reported no difference in the frequency of abnormal responses to vaccination $[97,100]$. Moreover, there is no study reporting that hepatitis B vaccines worsen AIIRD.

\section{4) Vaccination methods}

A 3-dose series (0, 1, and 6 months) of hepatitis B vac- cines should be administered to patients with AIIRD who have no hepatitis $B$ antibody. To non-responding patients not showing any sign of antibodies after administering 3 doses, it is recommended to administer another 3 doses of $(0,1$, and 6 months). No clear evidence yet exists of an accelerated schedule of hepatitis $B$ vaccines (for instance, $0,1,2$, and 12 months) or a high dose immunization for patients with AIIRD.

\section{Hepatitis A vaccine}

Hepatitis A vaccines should be considered for patients with AIIRD based on the same indication of healthy persons (LOE: Low/SOE: Weak recommendation).

\section{1) Vaccination targets}

There is no evidence that patients with AIIRD are more vulnerable to hepatitis $\mathrm{A}$ or have a higher risk of complications. Almost no statement regarding hepatitis A vaccination was observed in the guidelines for the vaccination of patients with AIIRD that was either published in-country or abroad $[22,23]$. However, it is generally recommended to administer hepatitis A vaccines to patients with AIIRD based on the same indication of healthy individuals. The KSID recommends administering hepatitis A vaccines to patients with chronic diseases; workers in childcare facilities; health care providers and laboratory workers in danger of being exposed to hepatitis $\mathrm{A}$ virus; restaurant workers; those who travel to or stay for a long time in areas where hepatitis A is prevalent; those who are frequently administered with blood components; male homosexuals; those who abuse narcotic injections; and those who contact patients with hepatitis A [96]. Considering the epidemiology of hepatitis A in Korea, it is recommended to administer vaccines to those aged $<40$ years without an antibody test, and to those aged $\geq 40$ years only after conducting an antibody test and confirming that they are antibody-negative [101].

\section{2) Effects and efficacy of vaccine}

The aforementioned research findings indicate that the immunogenicity of patients with AIIRD is not significantly lower than healthy individuals. Yet, those who are taking immunosuppressant therapies may show lower immunogenicity; therefore, hepatitis A vaccines should be administered, if feasible, prior to or following the administration of immunosuppressants. If the risk of 
infection is high due to exposure to the hepatitis A virus, hepatitis A vaccines should be administered even during immunosuppressive therapies.

\section{3) Safety of vaccine}

The indicated hepatitis A vaccines can be safely administered even in an immunocompromised state. Their side effects in patients with AIIRD are not different from those in healthy individuals [102].

\section{4) Vaccination methods}

In general, intramuscular injections are administered according to the instructions of the products. After the first vaccination, the second dose should be administered within $6 \sim 18$ months. When patients are receiving immunosuppressants, the timing of vaccination should be determined considering the disease conditions of patients, the immunosuppression level, and the medications' half-life period.

\section{Human papillomavirus vaccine}

Patients with AIIRD must be administered human papillomavirus (HPV) vaccines (LOE: Low/SOR: Strong recommendation).

\section{1) Vaccination targets}

A multi-center cross-sectional study conducted in Korea reported that patients with systemic lupus erythematosus showed a higher-risk human papilloma virus infection rate ( $24.6 \%$ vs. $7.9 \%$, odds ratio [OR] 3.8$)$ and a higher frequency of abnormalities in the results of a Pap smear test ( $16.4 \%$ vs. $2.8 \%$, OR 4.4 ) than a control group [103]. The systemic lupus erythematosus itself was an independent risk factor of the observed abnormalities (OR 3.5, 95\% CI 1.8 6.9), and there was no significant correlation with the use of immunosuppressants. The overall prevalence of HPV in patients with systemic lupus erythematosus was higher (11.8\% vs. $7.3 \%$ ), and that of multiple infections of HPV in patients with lupus was also higher $(4.7 \%$ vs. $1.1 \%)$ [104]. Whereas, the viru's removal rate in patients with systemic lupus erythematosus was lower than that of a general group [105]. HPV vaccines are recommended for young adults with AIIRD, particularly females aged between 13 and 16 years before having their first sexual contact, and no later than the age of 26 years $[23,25,106]$. In the United States, HPV vac- cines are allowed to be administered by the age of 45 years, but for those aged $>26$ years, vaccination should be determined considering their sexual contact history and immunosuppressive state. Patients with rheumatoid arthritis who are taking immunosuppressants, including biologic agents, are recommended to receive HPV vaccines when they are adapted [95]. Young male patients with AIIRD are also recommended to receive HPV vaccines should they have no vaccination history. Since many clinical studies reported that patients with systemic lupus erythematosus contracted HPV, vaccination should be highly considered.

\section{2) Effects and efficacy of vaccines}

The seroprevalence rate of HPV vaccines in patients with systemic lupus erythematosus is $76 \%$, which is lower than that of unaffected individuals (93\%). Those who were administered with a low-dose steroid showed significantly low potency of HPV-16 antibodies compared to those who were not administered with steroid $(1,870$ $\mathrm{mMU}$ vs. 3,818 mMU), and patients with systemic lupus erythematosus who were administered with the mycophenolate mofetil immunosuppresant tended to show a lower potency of HPV-6, -16, -18 antibodies [107]. These research results indicate that administrating immunosuppressants, such as steroids and mycophenolate mofetil, can lower the HPV's immunogenicity.

\section{3) Vaccine safety}

Inactivated HPV vaccines can be safely administered to patients with AIIRD regardless of their immunity state or the use of immunosuppressants. A recent case-control study that assessed the efficacy and safety of HPV vaccines in patients with systemic lupus erythematosus reported that there was no change in the activity of systemic lupus erythematosus for 1 year after vaccination [107]. The frequency and severity of abnormal responses were not different from healthy individuals, while there is no sufficient evidence that they worsen AIIRD. It was reported that blood clots were created after vaccination (relative risk, 0.2/100,000); however, most cases had a relevant risk factor [108]. Patients with antiphospholipid antibody syndrome need to be carefully observed after administering vaccines.

\section{4) Vaccination methods}

A primary series of HPV vaccines should be administered to female children aged between 11 and 12 
years. For those not vaccinated or with an incomplete 3-dose primary series, it is recommended to administer an HPV 4 or HPV 9 vaccine to females aged between 13 and 26 years and an HPV 2 vaccine to females aged between 13 and 25 years. In Korea, a three-dose series of human papilloma virus vaccines is recommended. The second dose should be administered 1 or 2 months after the first, and the third dose should be administered 6 months after the second. The first and second doses should be separated by at least 4 weeks, and the second and third doses should be separated at least by 5 months. Those who did not receive the second and third doses after the first dose and thus did not complete vaccination do not need the series again from the first dose, and additional doses should be administered according to the recommended vaccination schedule. In this case, they can be vaccinated even after their 26th birthday. Those who are taking immunosuppressants, including biologic agents, can also be administered HPV vaccines; but, vaccination is recommended when the disease's activity is stabilized.

\section{Tetanus-diphtheria-pertussis vaccine}

Patients with AIIRD have to take tetanus-diphtheriapertussis vaccines (LOE: Moderate/SOR: Strong recommendation).

\section{1) Vaccination targets}

Patients with AIIRD should be vaccinated against tetanus-diphtheria-pertussis, according to the general recommendations. When a contaminated injury was found in patients who received a rituximab therapy within the last 24 weeks, immunoglobulin is administered for passive immunity [23].

\section{2) Effects and efficacy of vaccine}

It is known that the immunogenicity of tetanus vaccines in patients with rheumatoid arthritis or systemic lupus erythematosus is lower than that of healthy individuals regardless of the administration of immunosuppressants [109]. There are various ways in which a decrease in the immunogenicity of vaccines caused by the use of immunosuppressants is observed, depending on the type of administered immunosuppressants. A slight decrease was observed in the case of methotrexate compared to healthy persons; however, the immunogenicity of vaccines in those who received combination therapies with methotrexate and rituximab was similar to the immunogenicity in those who were only administered methotrexate [110]. Although there was no study on patients with rheumatoid arthritis, the immunogenicity of healthy individuals who were administered tetanus vaccines 2 weeks after administering abatacept was reduced [111]. Those who were administered tetanus vaccines 8 weeks after administering abatacept showed similar immunogenicity compared to those who were administered with tetanus vaccines 2 weeks after receiving abatacept; but, the level was lower than that of those who did not receive abatacept. Patients with rheumatoid arthritis who were administered methotrexate and tocilizumab showed no significant difference regarding the immunogenicity of tetanus vaccines compared to those who were only administered methotrexate [36]. Some studies reported that the effects of tetanus-diphtheria-pertussis vaccines decreased in patients with systemic lupus erythematosus who showed high disease activity, but others reported opposite results, thus requiring an additional study [84,112-114].

\section{3) Safety of vaccine}

Tetanus-diphtheria (Td) vaccines for adults and inactivated tetanus-diphtheria-pertussis (Tdap) vaccines, can be safely administered to patients with AIIRD, regardless of their state of immunity or use of immunosuppressants. The frequency and severity of side effects are not different from that of healthy individuals, with no evidence that vaccination increases the activity of rheumatoid arthritis or systemic lupus erythematosus [84].

\section{4) Vaccination methods}

Td and Tdap vaccines can be administered to patients with AIIRD based on the same schedules for general adults. Adults aged 18 years or older who are not vaccinated with childhood DTP (Diphtheria toxoid, whole cell pertussis, and tetanus toxoid vaccine), who have no clear vaccination record, or who were born before 1958 (when domestic DTP was introduced) should be administered with 3 doses. The Tdap vaccine should be administrated first, and additionally given with the Td vaccine after $4 \sim 8$ weeks and $6 \sim 12$ months. If the $\mathrm{Td}$ vaccine is primarily administrated, then the second or third schedule constitutes the Tdap vaccine. Thereafter, the $\mathrm{Td}$ vaccine should be additionally administered every 10 years. Pregnant women should be given a Tdap vaccine every 27 36 weeks of pregnancy, regardless of the previous Td vaccine history or a Tdap vaccine to prevent pertussis in newborns. 


\section{Herpes zoster vaccine}

Herpes zoster vaccines should be considered for patients with AIIRD who are aged $\geq 50$ years (LOE: Very low/SOR: Weak recommendation).

\section{1) Vaccination targets}

The risk of herpes zoster infection in patients with AIIRD is increased by immunosuppressants or immune dysregulation. Not many epidemiological studies have been conducted on patients with AIIRD, but the risk of herpes zoster infection in patients with rheumatoid arthritis, systemic lupus erythematosus, granulomatosis with polyangiitis, polymyositis and dermatomyositis is known to be higher than healthy individuals [115]. The KSID fully recommends to administer herpes zoster vaccines to adults aged $\geq 60$ years regardless of their history of herpes zoster. In addition, it is recommended to determine whether to administer herpes zoster vaccines to adults aged 50 59 years based on the conditions of individuals. Most practice guidelines for patients with AIIRD published in other countries recommend to administer herpes zoster vaccines to patients with AIIRD who are aged $\geq 60$ years and are not severely immunocompromised $[23,26,95]$. Guidelines in Europe and the Centers for Disease Control and Prevention (CDC) of the United States state that herpes zoster vaccines can be administered even when using a low dose of methotrexate ( $<0.4 \mathrm{mg} / \mathrm{kg} /$ week or $<20 \mathrm{mg} /$ week), glucocorticoid (prednisolone, $<20 \mathrm{mg} /$ day), azathioprine ( $<3.0 \mathrm{mg} / \mathrm{kg} /$ day) and 6 -mercaptopurine $(<1.5 \mathrm{mg} / \mathrm{kg} /$ day $)$.

\section{2) Effects and efficacy of vaccines}

No prospective study exists regarding the clinical effects and safety of herpes zoster vaccines on patients with rheumatoid arthritis. Two large-scale retrospective studies were conducted regarding the effects of the herpes zoster vaccines on patients with AIIRD, including those who were administered with biologic agents. Their results reported that the prevalence of herpes zoster in those who were administered the vaccines was similar to the prevalence in those who did not; however, the risk of herpes zoster was reduced by $39 \%$ (29\% 48\%) $[116,117]$. Another retrospective study reported that those who were administered the herpes zoster vaccines showed a lower prevalence than those who were not; however, they found that the effects disappeared 5 years after vaccination [118]. A prospective pilot study targeting 10 patients with systemic lupus erythematosus also reported that their immunogenicity was slightly reduced, but was not significant [119].

\section{3) Safety of vaccine}

Herpes zoster vaccines that are currently distributed are live attenuated; thus, it should be carefully administered to those who receive immunosuppressants. Guidelines in Europe and the CDC of the United States state that herpes zoster vaccines can be administered even when using a low dose of methotrexate $(<0.4 \mathrm{mg} / \mathrm{kg} /$ week or $<20$ $\mathrm{mg} /$ week), glucocorticoid ( $<20 \mathrm{mg} /$ day prednisolone or equivalent), and azathioprine ( $<3.0 \mathrm{mg} / \mathrm{kg} /$ day). However, herpes zoster vaccines should not be administered to those who receive a high-dose steroid or immunosuppressant or a low dose of more than 2 types of immunosuppressants or biologic agents (adalimumab, infliximab, etanercept, etc.).

\section{4) Vaccination methods}

Herpes zoster vaccines that are currently distributed in Korea are one-time subcutaneously administered. The biggest issue regarding the herpes zoster vaccines is the emergence of Shingrix (GlaxoSmithKline Biologicals, Rixensart, Belgium), the recombinant zoster vaccine. The vaccine is yet to be introduced in Korea, and it will be a while before it is distributed. The two-dose series of Shingrix are intramuscularly injected, and, as the vaccine is inactivated, it is expected to remedy the disadvantages of live attenuated vaccines. The Advisory Committee on Immunization Practices (ACIP) in the United States recommends Shingrix administration to patients with rheumatoid arthritis. It has, however, deferred recommending Shingrix for immunocompromised patients or those who are receiving moderate or severe immunosuppressants [120].

\section{Measles-mumps-rubella vaccine}

AIIRD patients on biologics agents or immunosuppressants should avoid measles-mumps-rubella (MMR) vaccines (LOE: Very low/SOR: Weak against). MMR vaccines can be considered for those who have not been vaccinated, depending on the risk of being exposed to MMR virus (LOE: Very low/SOR: Weak recommendation). 


\section{1) Vaccination targets}

Live attenuated vaccines must not be administered to patients with AIIRD who are taking immunosuppressants; however, when the level of immunosuppressive therapies is low, MMR vaccines can be considered [23]. Epidemiological studies on MMR infections in patients with AIIRD are rare. Korea was certified by the World Health Organization as the country that eradicated measles in 2014. However, imported cases of measles have been intermittently reported. Since it is generally known that the risk of MMR infections and complications in patients with AIIRD is high, it is recommended to administer MMR vaccines to patients with AIIRD considering the state of immunity and the type of medications used when the risk of MMR infection is high and the risk of infections caused by live attenuated vaccines is low $[23,121]$.

\section{2) Effects and efficacy of vaccine}

The efficacy of MMR vaccines on patients with AIIRD has not been researched. Studies that targeted patients with juvenile arthritis reported both a maintained immunogenicity well after vaccination and the ineffectiveness of biologic agents including methotrexate and anti-TNF drugs on immunogenicity $[122,123]$. In conclusion, the immunogenicity of MMR vaccines can differ depending on the use of immunosuppressants and the type of medications; but, the level is generally assumed to be similar to or slightly lower than that of healthy individuals.

\section{3) Safety of vaccine}

Administering MMR vaccines should be avoided, if feasible, to those who are using biologic agents and immunosuppressants or to patients with AIIRD who are immunocompromised. This is due to the immunocompromised persons administered with live attenuated vaccines being infected by vaccine injections [124]. Unlike herpes zoster vaccines, the possibility of vaccination depending on the use and the dose of immunosuppressants are not mentioned in detail.

\section{4) Vaccination methods}

Administering the MMR vaccines to those who are contemplating travel to countries where measles is prevalent but whose level of immunity is uncertain is recommended. It should be determined whether to administer the vaccines to patients with AIIRD after checking their vaccination history, use of immunosuppressants, and an im- munocompromised state. After checking their vaccination history (not necessary to vaccinate those who contracted measles in the past or those whose measles antibodies are positive or those aged $\geq 51$ years), those who did not complete a 2-dose series of MMR vaccines or those who are not certain about their vaccination history are recommended to be administered with a 2-dose series of vaccines (at least 4 weeks apart) before traveling. Patients with AIIRD who are expecting pregnancy should be tested for rubella antibodies and if they are found to be antibody negative, they should be administered with vaccines. Still, it is recommended to administer vaccines at least 4 weeks prior to initiating immunosuppressive therapies. For those who are using immunosuppressants, the timing of vaccination should be determined considering the disease conditions of patients, and the immunosuppression level and the half-life period of the immunosuppressants.

\section{DISCUSSION AND CONCLUSIONS}

This practice guideline was developed to present the types of vaccines and the methods of vaccination suitable for Korean patients with AIIRD. This guideline is intended for clinicians and primary care providers. A practice guideline development committee was formed to review existing guidelines and adapt them to develop a proper guideline.

The content of this practice guideline is not far different from that of the existing practice guidelines. Since vaccination is the most effective way to prevent infectious diseases and the possibility that vaccinations may aggravate AIIRD is low, vaccinations should be actively considered for patients with AIIRD based on the guideline for vaccination of persons who are healthy and whose level of immunity is normal. To do so, the vaccination history of patients should be checked prior to initiating AIIRD treatment, and it is recommended to vaccinate them, if feasible, prior to the use of immunosuppressants. Most inactivated vaccines can be safely administered, but live attenuated vaccines should be avoided for patients with AIIRD who use immunosuppressants as much as possible. In addition, those who live in a household with patients with AIIRD and their care providers should be vaccinated based on the vaccination instructions for healthy individuals.

One of the limitations of these guidelines is the lack of evidence for developing this practice guideline. The prev- 
alence of AIIRD itself is low and the immunosuppression level and health conditions of patients differ. There are also various types of medications used to treat underlying diseases. For this reason, only a few high-quality randomized controlled studies have been conducted, making it difficult to systematically conduct a literature review. Moreover, there is almost no study that surveyed the vaccination status of Korean patients with AIIRD or analyzed the effects and impact of vaccines. Moreover, the opinions and needs of different groups were not reflected in the process of developing this practice guideline. Involving users in the process of developing and writing a guideline is effective in raising their sense of responsibility for, and inducing their interest in the developed guideline. For this reason, professionals in the field, such as doctors at general hospitals, practitioners, and nurses should be engaged in the process of development. It is also necessary to involve and collect feedback from patients in the process. Third, the applicability of this practice guideline was not sufficiently reviewed. The unique characteristics of the Korean health care systems were not sufficiently considered, and its applicability was not analyzed due to limited resources; therefore, the cost-effectiveness of vaccinations was not analyzed. Additionally, the distribution and implementation methods of this guideline were not discussed.

This is the first practice guideline regarding the vaccination of patients with AIIRD; therefore, it needs to be periodically revised, considering that new AIIRD medications continue to be developed and that new vaccines are also introduced.

\section{ACKNOWLEDGMENTS}

This work was supported by Korean College of Rheumatology and the Korean Society of Infectious Diseases.

\section{CONFLICT OF INTEREST}

No potential conflict of interest relevant to this article was reported.

\section{AUTHOR CONTRIBUTIONS}

Conceptualization: H.J.C., S.S.L. Data curation: C.H.J., S.J.J. Investigation: K.T.K., E.S.K., J.H.K., H.A.K., D.J.P., S.H.P., J.K.P., J.K.A., J.S.O., J.W.Y., J.H.L., H.Y.L., M.J.C.,
W.S.C., Y.H.C., J.H.C., J.Y.H. Methodology: H.Y.L. Supervision: H.J.C., S.S.L. Writing - original draft: Y.B.S., S.J.M. Writing - review \& editing: S.J.J., C.H.J., J.Y.S., Y.K.S.

\section{SUPPLEMENTARY DATA}

Supplementary data containing Korean version of this article is online at https://doi.org/10.4078/jrd.2020.27.3.182.

\section{REFERENCES}

1. Falagas ME, Voidonikola PT, Angelousi AG. Tuberculosis in patients with systemic rheumatic or pulmonary diseases treated with glucocorticosteroids and the preventive role of isoniazid: a review of the available evidence. Int J Antimicrob Agents 2007;30:477-86.

2. Rahier JF, Moutschen M, Van Gompel A, Van Ranst M, Louis E, Segaert S, et al. Vaccinations in patients with immune-mediated inflammatory diseases. Rheumatology (Oxford) 2010;49:1815-27.

3. Bosch X, Guilabert A, Pallarés L, Cerveral R, Ramos-Casals $\mathrm{M}$, Bové $\mathrm{A}$, et al. Infections in systemic lupus erythematosus: a prospective and controlled study of 110 patients. Lupus 2006;15:584-9.

4. Doran MF, Crowson CS, Pond GR, O'Fallon WM, Gabriel SE. Predictors of infection in rheumatoid arthritis. Arthritis Rheum 2002;46:2294-300.

5. Martin-Mola E, Balsa A. Infectious complications of biologic agents. Rheum Dis Clin North Am 2009;35:183-99.

6. Furst DE. The risk of infections with biologic therapies for rheumatoid arthritis. Semin Arthritis Rheum 2010;39: 327-46.

7. Glück T, Müller-Ladner U. Vaccination in patients with chronic rheumatic or autoimmune diseases. Clin Infect Dis 2008;46:1459-65.

8. Hmamouchi I, Winthrop K, Launay O, Dougados M. Low rate of influenza and pneumococcal vaccine coverage in rheumatoid arthritis: data from the international COMORA cohort. Vaccine 2015;33:1446-52.

9. Kim SY, Choi MY, Shin SS, Ji SM, Park JJ, Yoo JH, et al. Handbook for clinical practice guideline developer version 1.0. Seoul, National Entertainment Collectibles Association, 2015, p. 1-428.

10. Nohynek H, Jokinen J, Partinen M, Vaarala O, Kirjavainen $\mathrm{T}$, Sundman J, et al. ASO3 adjuvanted AH1N1 vaccine associated with an abrupt increase in the incidence of childhood narcolepsy in Finland. PLoS One 2012;7:e33536.

11. Partinen M, Kornum BR, Plazzi G, Jennum P, Julkunen I, Vaarala O. Narcolepsy as an autoimmune disease: the role of H1N1 infection and vaccination. Lancet Neurol 2014; 13:600-13.

12. Mantadakis E, Farmaki E, Buchanan GR. Thrombocytopenic purpura after measles-mumps-rubella vaccination: a systematic review of the literature and guidance for management. J Pediatr 2010;156:623-8.

13. Andrews N, Stowe J, Miller E, Svanström H, Johansen K, Bonhoeffer J, et al.; VAESCO consortium. A collaborative 
approach to investigating the risk of thrombocytopenic purpura after measles-mumps-rubella vaccination in England and Denmark. Vaccine 2012;30:3042-6.

14. Miller E, Waight P, Farrington CP, Andrews N, Stowe J, Taylor B. Idiopathic thrombocytopenic purpura and MMR vaccine. Arch Dis Child 2001;84:227-9.

15. Israeli E, Agmon-Levin N, Blank M, Shoenfeld Y. Adjuvants and autoimmunity. Lupus 2009;18:1217-25.

16. Wraith DC, Goldman M, Lambert PH. Vaccination and autoimmune disease: what is the evidence? Lancet 2003;362: 1659-66.

17. Perricone C, Colafrancesco S, Mazor RD, Soriano A, Agmon-Levin N, Shoenfeld Y. Autoimmune/inflammatory syndrome induced by adjuvants (ASIA) 2013: unveiling the pathogenic, clinical and diagnostic aspects. J Autoimmun 2013;47:1-16.

18. Louie JS, Nies KM, Shoji KT, Fraback RC, Abrass C, Border $\mathrm{W}$, et al. Clinical and antibody responses after influenza immunization in systemic lupus erythematosus. Ann Intern Med 1978;88:790-2.

19. Zycinska K, Romanowska M, Nowak I, Rybicka K, Wardyn KA, Brydak LB. Antibody response to inactivated subunit influenza vaccine in patients with Wegener's granulomatosis. J Physiol Pharmacol 2007;58 Suppl 5(Pt 2):819-28.

20. Ristow SC, Douglas RG Jr, Condemi JJ. Influenza vaccination of patients with systemic lupus erythematosus. Ann Intern Med 1978;88:786-9.

21. Rubin LG, Levin MJ, Ljungman P, Davies EG, Avery R, Tomblyn M, et al.; Infectious Diseases Society of America. 2013 IDSA clinical practice guideline for vaccination of the immunocompromised host. Clin Infect Dis 2014;58: 309-18.

22. Cordeiro I, Duarte AC, Ferreira JF, Gonçalves MJ, Meirinhos $\mathrm{T}$, Rocha TM, et al. Recommendations for vaccination in adult patients with systemic inflammatory rheumatic diseases from the Portuguese Society of Rheumatology. Acta Reumatol Port 2016;41:112-30.

23. van Assen S, Agmon-Levin N, Elkayam O, Cervera R, Doran MF, Dougados M, et al. EULAR recommendations for vaccination in adult patients with autoimmune inflammatory rheumatic diseases. Ann Rheum Dis 2011; 70:414-22.

24. Singh JA, Saag KG, Bridges SL Jr, Akl EA, Bannuru RR, Sullivan MC, et al. 2015 American College of Rheumatology guideline for the treatment of rheumatoid arthritis. Arthritis Rheumatol 2016;68:1-26.

25. Bühler S, Eperon G, Ribi C, Kyburz D, van Gompel F, Visser LG, et al. Vaccination recommendations for adult patients with autoimmune inflammatory rheumatic diseases. Swiss Med Wkly 2015;145:w14159.

26. Bombardier C, Hazlewood GS, Akhavan P, Schieir O, Dooley A, Haraoui B, et al.; Canadian Rheumatology Association. Canadian Rheumatology Association recommendations for the pharmacological management of rheumatoid arthritis with traditional and biologic diseasemodifying antirheumatic drugs: part II safety. J Rheumatol 2012;39:1583-602.

27. Ledingham J, Deighton C; British Society for Rheumatology Standards, Guidelines and Audit Working Group. Update on the British Society for Rheumatology guidelines for prescribing TNFalpha blockers in adults with rheumatoid ar- thritis (update of previous guidelines of April 2001). Rheumatology (Oxford) 2005;44:157-63.

28. Pham T, Fautrel B, Gottenberg JE, Goupille P, Hachulla E, Masson C, et al.; Rheumatic Diseases \& Inflammation Group (Club Rhumatismes et Inflammation, CRI) of the French Society for Rheumatology (Société Française de Rhumatologie, SFR). Rituximab (MabThera) therapy and safety management. Clinical tool guide. Joint Bone Spine 2008;75 Suppl 1:S1-99.

29. Pham T, Claudepierre P, Constantin A, de Bandt M, Fautrel B, Gossec L, et al.; Club Rhumatismes et Inflammation (CRI). Tocilizumab: therapy and safety management. Joint Bone Spine 2010;77 Suppl 1:S3-100.

30. Pham T, Claudepierre P, Constantin A, Fautrel B, Gossec L, Gottenberg JE, et al. Abatacept therapy and safety management. Joint Bone Spine 2009;76 Suppl 1:S3-55.

31. Pham T, Claudepierre P, Deprez X, Fautrel B, Goupille P, Hilliquin P, et al.; Club Rhumatismes et Inflammation, French Society of Rheumatology. Anti-TNF alpha therapy and safety monitoring. Clinical tool guide elaborated by the Club Rhumatismes et Inflammations (CRI), section of the French Society of Rheumatology (Société Française de Rhumatologie, SFR). Joint Bone Spine 2005;72 Suppl 1:S1-58.

32. Kapetanovic MC, Saxne T, Sjöholm A, Truedsson L, Jönsson G, Geborek P. Influence of methotrexate, TNF blockers and prednisolone on antibody responses to pneumococcal polysaccharide vaccine in patients with rheumatoid arthritis. Rheumatology (Oxford) 2006;45:106-11.

33. Gelinck LB, van der Bijl AE, Visser LG, Huizinga TW, van Hogezand RA, Rijkers GT, et al. Synergistic immunosuppressive effect of anti-TNF combined with methotrexate on antibody responses to the 23 valent pneumococcal polysaccharide vaccine. Vaccine 2008;26:3528-33.

34. Kaine JL, Kivitz AJ, Birbara C, Luo AY. Immune responses following administration of influenza and pneumococcal vaccines to patients with rheumatoid arthritis receiving adalimumab. J Rheumatol 2007;34:272-9.

35. Ribeiro AC, Laurindo IM, Guedes LK, Saad CG, Moraes JC, Silva CA, et al. Abatacept and reduced immune response to pandemic 2009 influenza A/H1N1 vaccination in patients with rheumatoid arthritis. Arthritis Care Res (Hoboken) 2013;65:476-80.

36. Bingham CO 3rd, Rizzo W, Kivitz A, Hassanali A, Upmanyu R, Klearman M. Humoral immune response to vaccines in patients with rheumatoid arthritis treated with tocilizumab: results of a randomised controlled trial (VISARA). Ann Rheum Dis 2015;74:818-22.

37. Hua C, Barnetche T, Combe B, Morel J. Effect of methotrexate, anti-tumor necrosis factor $\alpha$, and rituximab on the immune response to influenza and pneumococcal vaccines in patients with rheumatoid arthritis: a systematic review and meta-analysis. Arthritis Care Res (Hoboken) 2014;66: 1016-26.

38. Morel J, Czitrom SG, Mallick A, Sellam J, Sibilia J. Vaccinations in adults with chronic inflammatory joint disease: immunization schedule and recommendations for patients taking synthetic or biological disease-modifying antirheumatic drugs. Joint Bone Spine 2016;83:135-41.

39. Brenol CV, Azevedo VF, Bonvehi PE, Coral-Alvarado PX, Granados J, Muñoz-Louis R, et al. Vaccination recom- 
mendations for adults with autoimmune inflammatory rheumatic diseases in Latin America. J Clin Rheumatol 2018;24:138-47.

40. Tanrıöver MD, Akar S, Türkçapar N, Karadağ Ö, Ertenli İ, Kiraz S. Vaccination recommendations for adult patients with rheumatic diseases. Eur J Rheumatol 2016;3:29-35.

41. Staples JE, Gershman M, Fischer M; Centers for Disease Control and Prevention (CDC). Yellow fever vaccine: recommendations of the Advisory Committee on Immunization Practices (ACIP). MMWR Recomm Rep 2010;59:1-27.

42. Potter J, Stott DJ, Roberts MA, Elder AG, O'Donnell B, Knight PV, et al. Influenza vaccination of health care workers in long-term-care hospitals reduces the mortality of elderly patients. J Infect Dis 1997;175:1-6.

43. Carman WF, Elder AG, Wallace LA, McAulay K, Walker A, Murray GD, et al. Effects of influenza vaccination of health-care workers on mortality of elderly people in longterm care: a randomised controlled trial. Lancet 2000;355: 93-7.

44. Babcock HM, Gemeinhart N, Jones M, Dunagan WC, Woeltje KF. Mandatory influenza vaccination of health care workers: translating policy to practice. Clin Infect Dis 2010;50:459-64.

45. Pearson ML, Bridges CB, Harper SA; Healthcare Infection Control Practices Advisory Committee (HICPAC); Advisory Committee on Immunization Practices (ACIP). Influenza vaccination of health-care personnel: recommendations of the Healthcare Infection Control Practices Advisory Committee (HICPAC) and the Advisory Committee on Immunization Practices (ACIP). MMWR Recomm Rep 2006;55:1-16.

46. Marin M, Güris D, Chaves SS, Schmid S, Seward JF; Advisory Committee on Immunization Practices, Centers for Disease Control and Prevention (CDC). Prevention of varicella: recommendations of the Advisory Committee on Immunization Practices (ACIP). MMWR Recomm Rep 2007;56:1-40.

47. Sharrar RG, LaRussa P, Galea SA, Steinberg SP, Sweet AR, Keatley RM, et al. The postmarketing safety profile of varicella vaccine. Vaccine 2000;19:916-23.

48. Grossberg R, Harpaz R, Rubtcova E, Loparev V, Seward JF, Schmid DS. Secondary transmission of varicella vaccine virus in a chronic care facility for children. J Pediatr 2006; 148:842-4.

49. Nichol KL, Wuorenma J, von Sternberg T. Benefits of influenza vaccination for low-, intermediate-, and high-risk senior citizens. Arch Intern Med 1998;158:1769-76.

50. Blumentals WA, Arreglado A, Napalkov P, Toovey S. Rheumatoid arthritis and the incidence of influenza and influenza-related complications: a retrospective cohort study. BMC Musculoskelet Disord 2012;13:158.

51. Chalmers A, Scheifele D, Patterson C, Williams D, Weber J, Shuckett R, et al. Immunization of patients with rheumatoid arthritis against influenza: a study of vaccine safety and immunogenicity. J Rheumatol 1994;21:1203-6.

52. Del Porto F, Laganà B, Biselli R, Donatelli I, Campitelli L, Nisini R, et al. Influenza vaccine administration in patients with systemic lupus erythematosus and rheumatoid arthritis. Safety and immunogenicity. Vaccine 2006;24:3217-23.

53. Denman EJ, Denman AM, Greenwood BM, Gall D, Heath RB. Failure of cytotoxic drugs to suppress immune re- sponses of patients with rheumatoid arthritis. Ann Rheum Dis 1970;29:220-31.

54. Elkayam O, Bashkin A, Mandelboim M, Litinsky I, Comaheshter D, Levartovsky D, et al. The effect of infliximab and timing of vaccination on the humoral response to influenza vaccination in patients with rheumatoid arthritis and ankylosing spondylitis. Semin Arthritis Rheum 2010;39:442-7.

55. Fomin I, Caspi D, Levy V, Varsano N, Shalev Y, Paran D, et al. Vaccination against influenza in rheumatoid arthritis: the effect of disease modifying drugs, including TNF alpha blockers. Ann Rheum Dis 2006;65:191-4.

56. Gelinck LB, van der Bijl AE, Beyer WE, Visser LG, Huizinga TW, van Hogezand RA, et al. The effect of anti-tumour necrosis factor alpha treatment on the antibody response to influenza vaccination. Ann Rheum Dis 2008; 67:713-6.

57. Herron A, Dettleff G, Hixon B, Brandwin L, Ortbals D, Hornick R, et al. Influenza vaccination in patients with rheumatic diseases. Safety and efficacy. JAMA 1979;242: 53-6.

58. Kubota T, Nii T, Nanki T, Kohsaka H, Harigai M, Komano Y, et al. Anti-tumor necrosis factor therapy does not diminish the immune response to influenza vaccine in Japanese patients with rheumatoid arthritis. Mod Rheumatol 2007;17:531-3.

59. Nii T, Kubota T, Nanki T, Komano Y, Harigai M, Kohsaka $\mathrm{H}$, et al. Reevaluation of antibody titers 1 year after influenza vaccination in patients with rheumatoid arthritis receiving TNF blockers. Mod Rheumatol 2009;19:216-8.

60. Turner-Stokes L, Cambridge G, Corcoran T, Oxford JS, Snaith ML. In vitro response to influenza immunisation by peripheral blood mononuclear cells from patients with systemic lupus erythematosus and other autoimmune diseases. Ann Rheum Dis 1988;47:532-5.

61. van Assen S, Holvast A, Benne CA, Posthumus MD, van Leeuwen MA, Voskuyl AE, et al. Humoral responses after influenza vaccination are severely reduced in patients with rheumatoid arthritis treated with rituximab. Arthritis Rheum 2010;62:75-81.

62. Williams GW, Steinberg AD, Reinertsen JL, Klassen LW, Decker JL, Dolin R. Influenza immunization in systemic lupus eruthematosus. A double-blind trial. Ann Intern Med 1978;88:729-34.

63. Holvast B, Huckriede A, Kallenberg CG, Bijl M. Influenza vaccination in systemic lupus erythematosus: safe and protective? Autoimmun Rev 2007;6:300-5.

64. Mercado U, Acosta H, Avendaño L. Influenza vaccination of patients with systemic lupus erythematosus. Rev Invest Clin 2004;56:16-20.

65. Wiesik-Szewczyk E, Romanowska M, Mielnik P, ChwalińskaSadowska H, Brydak LB, Olesińska M, et al. Anti-influenza vaccination in systemic lupus erythematosus patients: an analysis of specific humoral response and vaccination safety. Clin Rheumatol 2010;29:605-13.

66. Caza T, Oaks Z, Perl A. Interplay of infections, autoimmunity, and immunosuppression in systemic lupus erythematosus. Int Rev Immunol 2014;33:330-63.

67. Borba EF, Saad CG, Pasoto SG, Calich AL, Aikawa NE, Ribeiro $\mathrm{AC}$, et al. Influenza $\mathrm{A} / \mathrm{H} 1 \mathrm{~N} 1$ vaccination of patients with SLE: can antimalarial drugs restore diminished 
response under immunosuppressive therapy? Rheumatology (Oxford) 2012;51:1061-9.

68. Brodman R, Gilfillan R, Glass D, Schur PH. Influenzal vaccine response in systemic lupus erythematosus. Ann Intern Med 1978;88:735-40.

69. Pons VG, Reinertsen JL, Steinberg AD, Dolin R. Decreased cell-mediated cytotoxicity against virus-infected cells in systemic lupus erythematosus. J Med Virol 1979;4:15-23.

70. Holvast A, van Assen S, de Haan A, Huckriede A, Benne CA, Westra J, et al. Studies of cell-mediated immune responses to influenza vaccination in systemic lupus erythematosus. Arthritis Rheum 2009;60:2438-47.

71. Setti M, Fenoglio D, Ansaldi F, Filaci G, Bacilieri S, Sticchi $\mathrm{L}$, et al. Flu vaccination with a virosomal vaccine does not affect clinical course and immunological parameters in scleroderma patients. Vaccine 2009;27:3367-72.

72. Holvast A, Stegeman CA, Benne CA, Huckriede A, Wilschut JC, Palache AM, et al. Wegener's granulomatosis patients show an adequate antibody response to influenza vaccination. Ann Rheum Dis 2009;68:873-8.

73. Pasoto SG, Ribeiro AC, Viana VS, Leon EP, Bueno C, Neto $\mathrm{ML}$, et al. Short and long-term effects of pandemic unadjuvanted influenza $\mathrm{A}(\mathrm{H} 1 \mathrm{N1})$ pdm09 vaccine on clinical manifestations and autoantibody profile in primary Sjögren's syndrome. Vaccine 2013;31:1793-8.

74. Kobashigawa $T$, Nakajima A, Taniguchi A, Inoue E, Tanaka E, Momohara S, et al. Vaccination against seasonal influenza is effective in Japanese patients with rheumatoid arthritis enrolled in a large observational cohort. Scand J Rheumatol 2013;42:445-50.

75. Stojanovich L. Influenza vaccination of patients with systemic lupus erythematosus (SLE) and rheumatoid arthritis (RA). Clin Dev Immunol 2006;13:373-5.

76. Torres A, Peetermans WE, Viegi G, Blasi F. Risk factors for community-acquired pneumonia in adults in Europe: a literature review. Thorax 2013;68:1057-65.

77. Rákóczi É, Szekanecz Z. Pneumococcal vaccination in autoimmune rheumatic diseases. RMD Open 2017;3:e000484.

78. Elkayam O, Paran D, Caspi D, Litinsky I, Yaron M, Charboneau D, et al. Immunogenicity and safety of pneumococcal vaccination in patients with rheumatoid arthritis or systemic lupus erythematosus. Clin Infect Dis 2002;34: 147-53.

79. Karsh J, Pavlidis N, Schiffman G, Moutsopoulos HM. Immunization of patients with Sjögren's syndrome with pneumococcal polysaccharide vaccine: a randomized trial. Arthritis Rheum 1980;23:1294-8.

80. Hesselstrand R, Nagel J, Saxne T, Geborek P, Skattum L, Kapetanovic MC. Immunogenicity and safety of pneumococcal vaccination in patients with systemic sclerosis. Rheumatology (Oxford) 2018;57:625-30.

81. Nived P, Saxne T, Geborek P, Mandl T, Skattum L, Kapetanovic MC. Antibody response to 13-valent pneumococcal conjugate vaccine is not impaired in patients with rheumatoid arthritis or primary Sjögren's syndrome without disease modifying treatment. BMC Rheumatol 2018;2:12.

82. Grabar S, Groh M, Bahuaud M, Le Guern V, CostedoatChalumeau N, Mathian A, et al. Pneumococcal vaccination in patients with systemic lupus erythematosus: a multicenter placebo-controlled randomized double-blind study. Vaccine 2017;35:4877-85.
83. Nived P, Nagel J, Saxne T, Geborek P, Jönsson G, Skattum $\mathrm{L}$, et al. Immune response to pneumococcal conjugate vaccine in patients with systemic vasculitis receiving standard of care therapy. Vaccine 2017;35:3639-46.

84. Battafarano DF, Battafarano NJ, Larsen L, Dyer PD, Older SA, Muehlbauer S, et al. Antigen-specific antibody responses in lupus patients following immunization. Arthritis Rheum 1998;41:1828-34.

85. Izumi $Y$, Akazawa $M$, Akeda $Y$, Tohma S, Hirano F, Ideguchi $\mathrm{H}$, et al. The 23-valent pneumococcal polysaccharide vaccine in patients with rheumatoid arthritis: a double-blinded, randomized, placebo-controlled trial. Arthritis Res Ther 2017;19:15.

86. Watad A, Quaresma M, Brown S, Cohen Tervaert JW, Rodríguez-Pint I, Cervera R, et al. Autoimmune/inflammatory syndrome induced by adjuvants (Shoenfeld's syndrome)- an update. Lupus 2017;26:675-81.

87. Hügle T, Bircher A, Walker UA. Streptococcal hypersensitivity reloaded: severe inflammatory syndrome in Behcet's disease following 23-valent polysaccharide Streptococcus pneumoniae vaccine. Rheumatology (Oxford) 2012;51:761-2.

88. Felicetti P, Trotta F, Bonetto C, Santuccio C, Brauchli Pernus Y, Burgner D, et al. Spontaneous reports of vasculitis as an adverse event following immunization: a descriptive analysis across three international databases. Vaccine 2016;34:6634-40.

89. Choi MJ, Kang SO, Oh JJ, Park SB, Kim MJ, Cheong HJ. Cost-effectiveness analysis of 13-valent pneumococcal conjugate vaccine versus 23 -valent pneumococcal polysaccharide vaccine in an adult population in South Korea. Hum Vaccin Immunother 2018;14:1914-22.

90. Russell FM, Carapetis JR, Balloch A, Licciardi PV, Jenney AW, Tikoduadua L, et al. Hyporesponsiveness to re-challenge dose following pneumococcal polysaccharide vaccine at 12 months of age, a randomized controlled trial. Vaccine 2010;28:3341-9.

91. Tanaka E, Urata Y. Risk of hepatitis B reactivation in patients treated with tumor necrosis factor- $\alpha$ inhibitors. Hepatol Res 2012;42:333-9.

92. Oshima $\mathrm{Y}$, Tsukamoto $\mathrm{H}$, Tojo A. Association of hepatitis B with antirheumatic drugs: a case-control study. Mod Rheumatol 2013;23:694-704.

93. Xuan D, Yu Y, Shao L, Wang J, Zhang W, Zou H. Hepatitis reactivation in patients with rheumatic diseases after immunosuppressive therapy--a report of long-term follow-up of serial cases and literature review. Clin Rheumatol 2014;33:577-86.

94. Chen MH, Chen MH, Liu CY, Tsai CY, Huang DF, Lin HY, et al. Hepatitis B virus reactivation in rheumatoid arthritis patients undergoing biologics treatment. J Infect Dis 2017;215:566-73.

95. Singh JA, Saag KG, Bridges SL Jr, Akl EA, Bannuru RR, Sullivan MC, et al. 2015 American College of Rheumatology guideline for the treatment of rheumatoid arthritis. Arthritis Care Res (Hoboken) 2016;68:1-25.

96. The Korean Society of Infectious Diseases. Vaccination for adult. 2nd ed. Seoul, MIP, 2012.

97. IntongkamS, Samakarnthai P, Pakchotanon R, Narongroeknawin P, Assavatanabodee P, Chaiamnuay S. Efficacy and safety of hepatitis B vaccination in rheumatoid arthritis patients 
receiving disease-modifying antirheumatic drugs and/or biologics therapy. J Clin Rheumatol 2019;25:329-34.

98. Lan JL, Chen YM, Hsieh TY, Chen YH, Hsieh CW, Chen DY, et al. Kinetics of viral loads and risk of hepatitis B virus reactivation in hepatitis $\mathrm{B}$ core antibody-positive rheumatoid arthritis patients undergoing anti-tumour necrosis factor alpha therapy. Ann Rheum Dis 2011;70:1719-25.

99. Wang Q, Klenerman P, Semmo N. Significance of anti-HBc alone serological status in clinical practice. Lancet Gastroenterol Hepatol 2017;2:123-34.

100. Elkayam O, Yaron M, Caspi D. Safety and efficacy of vaccination against hepatitis $B$ in patients with rheumatoid arthritis. Ann Rheum Dis 2002;61:623-5.

101. Kim KA, Lee A, Ki M, Jeong SH. Nationwide seropositivity of hepatitis A in Republic of Korea from 2005 to 2014, before and after the outbreak peak in 2009. PLoS One 2017;12:e0170432.

102. Askling HH, Rombo L, van Vollenhoven R, Hallén I, Thörner $\AA$, Nordin M, et al. Hepatitis A vaccine for immunosuppressed patients with rheumatoid arthritis: a prospective, open-label, multi-centre study. Travel Med Infect Dis 2014;12:134-42.

103. Lee YH, Choe JY, Park SH, Park YW, Lee SS, Kang YM, et al. Prevalence of human papilloma virus infections and cervical cytological abnormalities among Korean women with systemic lupus erythematosus. J Korean Med Sci 2010;25: 1431-7.

104. Tam LS, Chan AY, Chan PK, Chang AR, Li EK. Increased prevalence of squamous intraepithelial lesions in systemic lupus erythematosus: association with human papillomavirus infection. Arthritis Rheum 2004;50:3619-25.

105. Tam LS, Chan PK, Ho SC, Yu MM, Yim SF, Cheung TH, et al. Natural history of cervical papilloma virus infection in systemic lupus erythematosus- a prospective cohort study. J Rheumatol 2010;37:330-40.

106. Anderson EJ. Rotavirus vaccines: viral shedding and risk of transmission. Lancet Infect Dis 2008;8:642-9.

107. Mok CC, Ho LY, Fong LS, To CH. Immunogenicity and safety of a quadrivalent human papillomavirus vaccine in patients with systemic lupus erythematosus: a case-control study. Ann Rheum Dis 2013;72:659-64.

108. Slade BA, Leidel L, Vellozzi C, Woo EJ, Hua W, Sutherland A, et al. Postlicensure safety surveillance for quadrivalent human papillomavirus recombinant vaccine. JAMA 2009; 302:750-7.

109. Nies K, Boyer R, Stevens R, Louie J. Anti-tetanus toxoid antibody synthesis after booster immunization in systemic lupus erythematosus. Comparison of the in vitro and in vivo responses. Arthritis Rheum 1980;23:1343-50.

110. Bingham CO 3rd, Looney RJ, Deodhar A, Halsey N, Greenwald $\mathrm{M}$, Codding $\mathrm{C}$, et al. Immunization responses in rheumatoid arthritis patients treated with rituximab: results from a controlled clinical trial. Arthritis Rheum 2010;62:64-74.

111. Tay L, Leon F, Vratsanos G, Raymond R, Corbo M. Vaccination response to tetanus toxoid and 23-valent pneumococcal vaccines following administration of a single dose of abatacept: a randomized, open-label, parallel group study in healthy subjects. Arthritis Res Ther 2007;9:R38.

112. Abe T, Homma M. Immunological reactivity in patients with systemic lupus erythematosus. Humoral antibody and cellular immune responses. Acta Rheumatol Scand 1971;17:35-46.

113. Devey ME, Bleasdale K, Isenberg DA. Antibody affinity and IgG subclass of responses to tetanus toxoid in patients with rheumatoid arthritis and systemic lupus erythematosus. Clin Exp Immunol 1987;68:562-9.

114. Kashef S, Ghazizadeh F, Derakhshan A, Farjadian S, Alyasin S. Antigen-specific antibody response in juvenile-onset SLE patients following routine immunization with tetanus toxoid. Iran J Immunol 2008;5:181-4.

115. Westra J, Rondaan C, van Assen S, Bijl M. Vaccination of patients with autoimmune inflammatory rheumatic diseases. Nat Rev Rheumatol 2015;11:135-45.

116. Zhang J, Delzell E, Xie F, Baddley JW, Spettell C, McMahan $\mathrm{RM}$, et al. The use, safety, and effectiveness of herpes zoster vaccination in individuals with inflammatory and autoimmune diseases: a longitudinal observational study. Arthritis Res Ther 2011;13:R174.

117. Zhang J, Xie F, Delzell E, Chen L, Winthrop KL, Lewis JD, et al. Association between vaccination for herpes zoster and risk of herpes zoster infection among older patients with selected immune-mediated diseases. JAMA 2012; 308:43-9.

118. Yun H, Xie F, Baddley JW, Winthrop K, Saag KG, Curtis JR. Longterm effectiveness of herpes zoster vaccine among patients with autoimmune and inflammatory diseases. J Rheumatol 2017;44:1083-7.

119. Guthridge JM, Cogman A, Merrill JT, Macwana S, Bean KM, Powe T, et al. Herpes zoster vaccination in SLE: a pilot study of immunogenicity. J Rheumatol 2013;40:1875-80.

120. Dooling KL, Guo A, Patel M, Lee GM, Moore K, Belongia EA, et al. Recommendations of the advisory committee on immunization practices for use of herpes zoster vaccines. MMWR Morb Mortal Wkly Rep 2018;67:103-8.

121. Shearer WT, Fleisher TA, Buckley RH, Ballas Z, Ballow M, Blaese RM, et al. Recommendations for live viral and bacterial vaccines in immunodeficient patients and their close contacts. J Allergy Clin Immunol 2014;133:961-6.

122. Heijstek MW, Kamphuis S, Armbrust W, Swart J, Gorter S, de Vries LD, et al. Effects of the live attenuated measles-mumps-rubella booster vaccination on disease activity in patients with juvenile idiopathic arthritis: a randomized trial. JAMA 2013;309:2449-56.

123. Borte S, Liebert UG, Borte M, Sack U. Efficacy of measles, mumps and rubella revaccination in children with juvenile idiopathic arthritis treated with methotrexate and etanercept. Rheumatology (Oxford) 2009;48:144-8.

124. Croce E, Hatz C, Jonker EF, Visser LG, Jaeger VK, Bühler $S$. Safety of live vaccinations on immunosuppressive therapy in patients with immune-mediated inflammatory diseases, solid organ transplantation or after bone-marrow transplantation- a systematic review of randomized trials, observational studies and case reports. Vaccine 2017;35: 1216-26. 